\title{
Cambios en la política de seguridad vial en España entre 2004 y 2010: Un análisis centrado en el diseño institucional ${ }^{1}$
}

\author{
Jordi Tena Sánchez \\ Investigador del Departamento de Sociología \\ Universitat Autònoma de Barcelona
}

Recibido: 07.07.2010

Aceptado: 02.09 .2010

\begin{abstract}
Resumen: En el presente trabajo se llevará a cabo un repaso sin ánimo de exhaustividad de los cambios más destacados que se han producido en la política de seguridad vial en España desde el 2004 hasta nuestros días desde la perspectiva del diseño institucional. Se sostiene que la política de seguridad vial había sido tradicionalmente errática en España. El problema no era percibido como tal por el conjunto de la población, y tanto las leyes como sus instrumentos de aplicación eran insuficientes y estaban mal diseñados. Pese a que éste es, lógicamente, un proceso de largo alcance, a partir de 2004 se produce un salto adelante cualitativo en este terreno. Entre otros muchos cambios, se modifica la Ley de Tráfico y Seguridad Vial para introducir el denominado carné por puntos, se reforma el Código Penal con el objetivo básico de definir mejor los delitos relacionados con la seguridad vial, y se aumentan de manera considerable los mecanismos de control del alcohol y la velocidad en las carreteras.
\end{abstract}

Palabras clave: diseño institucional, seguridad vial, carné por puntos, reforma del Código Penal.

Abstract: In this work, I will review the most important changes carried out in Spanish road safety policies since 2004 from the point of view of institutional design. I argue road safety policy had been erratic in Spain. Citizens did not think road safety to be a problem, and both laws and enforcement mechanisms were wrongly design. In spite of being a long scope process, in 2004 there was a qualitative change. Among many other changes, Traffic and Road Safety Law was modified to introduce the penalty points driving licence, Criminal Code was amended to define better offences related to road safety, and mechanisms to control alcohol and speed increased.

Key words: institutional design, road safety, penalty points driving licence, Criminal Code amendments.

${ }^{1}$ El presente trabajo se ha desarrollado en el marco de un Proyecto I+D+I con referencia CSO2009-09890 y de un proyecto CONSOLIDER-INGENIO con referencia CSD 201000034, ambos financiados por el Ministerio de Ciencia e Innovación (MICINN). 
Sumario: 1. Introducción.-2. La política de seguridad vial en España antes de las últimas reformas. 2.1. La progresiva concienciación de estar ante un problema. 2.2. Año 2003: El agotamiento de un modelo. 2.2.1. El tratamiento del alcohol y la velocidad. 2.2.2. La conducción con temeridad manifiesta. 2.2.3. La conducción con consciente desprecio por la vida de los demás. 2.2.4. Lesiones y muertes. 2.2.5. La conducción sin licencia. 2.3. Los instrumentos de aplicación de la legislación.-3. La política de seguridad vial entre el 2004 y el 2010. 3.1. La reforma de la Ley de tráfico y seguridad vial: el carné por puntos y los cursos de sensibilización. 3.2. La reforma del Código Penal en materia de tráfico y seguridad vial de 2007. 3.2.1. Artículo 47: nuevo efecto de la pena de privación del derecho de conducir. 3.2.2. Artículo 379: exceso de velocidad y conducción bajo la influencia de bebidas alcohólicas y drogas tóxicas. 3.2.3. Artículo 380: la conducción con temeridad manifiesta. 3.2.4. Artículo 381: la conducción con manifiesto desprecio por la vida de los demás. 3.2.5. Artículo 382: las lesiones. 3.2.6. Artículo 383: desobediencia por negativa a someterse a las pruebas de control. 3.2.7. Artículo 384: quebrantamiento de condena o de resolución administrativa. 3.2.8. Artículo 385: otras conductas de riesgo para la seguridad vial. 3.3. Otros cambios relevantes. - 4. Conclusiones.-Bibliografía.

\section{Introducción}

En el presente trabajo se llevará a cabo un repaso sin ánimo de exhaustividad de los cambios más destacados que se han producido en la política de seguridad vial en España desde el 2004 hasta nuestros días desde la perspectiva del diseño institucional.

El principal objetivo de la política de seguridad vial de cualquier país es, obviamente, reducir la siniestralidad. En este sentido, el principal ámbito de actuación de dicha política (aunque no el único, claro está) lo constituye la conducta de los conductores, dado que el denominado factor humano se encuentra tras el $90 \%$ de los accidentes de tráfico en los países desarrolla$\operatorname{dos}^{2}$. Más concretamente, las infracciones en general, y el alcohol y la velocidad excesiva o inadecuada ${ }^{3}$ en particular, son los principales desencadenantes de la accidentalidad viaria en España ${ }^{4}$. Se ofrecerán algunas cifras a

${ }^{2}$ Montoro (2008), Montoro y Roca (2007), Montoro, Roca y Tortosa (2008), Pérez (2003), Tortosa, Montoro, Roca y Civera (2006), Valdés (1978), Vargas (2007).

${ }^{3}$ La velocidad es excesiva cuando sobrepasa los límites legales. La velocidad es inadecuada cuando no se adapta a las condiciones de la vía o del conductor. Normalmente la velocidad inadecuada lo es porque es excesiva, pero esto no tiene porque ser siempre así. Por ejemplo, la velocidad legalmente permitida en un tramo de vía determinado puede ser excesiva en un momento particular si se dan factores excepcionales como lluvia intensa o niebla. A la inversa, una velocidad anormalmente reducida también puede ser inadecuada.

${ }^{4}$ Blasco (2008), Pérez (2003), Pumpido (2007), Tortosa (2008), Villalba (2008). 
modo de ilustración. Pérez (2003) sostiene que un 50\% de los accidentes se encuentra relacionado con violaciones de las normas de circulación (sin contar las infracciones relacionadas con el alcohol y la velocidad), un $25 \%$ con la velocidad excesiva o inadecuada y un $12 \%$ con el alcohol. Pumpido (2007) apunta que las estadísticas anteriores a la reforma del Código Penal de 2007 mostraban que el alcohol se encontraba presente en un $36 \%$ de los accidentes. El problema se vuelve más alarmante cuando nos centramos en los accidentes con muertos y heridos graves. Pérez (2003) señala que entre el $40 \%$ y $80 \%$ de los muertos en carretera presenta más de $0,5 \mathrm{~g} / 1$ de alcohol en sangre $^{5}$. En el mismo sentido diversos estudios han demostrado que las posibilidades de causar un accidente con $1 \mathrm{~g} / \mathrm{l}$ de alcohol en sangre se multiplican por 8 respecto a la situación en la que no se ha bebido. Con $1,5 \mathrm{~g} / \mathrm{l}$ dicha probabilidad se multiplica por 16 (Villalba, 2008). Estudios similares demuestran que la velocidad no sólo aumenta la frecuencia de los accidentes sino que también agrava sus consecuencias. Un aumento de la velocidad del 5\% conlleva un incremento del $10 \%$ del número de accidentes y del $20 \%$ de las muertes (Villalba, 2008). Por otra parte, con los sistemas de protección actuales, la probabilidad de morir en un accidente cuando hay exceso de velocidad se elevan un $50 \%$ y las de resultar herido grave en un $60 \%$. Finalmente, según los mismos estudios, en caso de impacto a $180 \mathrm{~km} / \mathrm{h}$ la probabilidad de morir es cercana al 100\% (Pérez, 2003). Este rápido repaso de algunos datos permite comprender el porqué la política de tráfico y seguridad vial debe en primer lugar tratar incidir sobre la conducta de los conductores, aunque sin descuidar, obviamente, otros aspectos de la misma como los vehículos y las infraestructuras.

En lo referido a la incidencia sobre la conducta de los conductores, la política de seguridad vial cuenta con tres ejes básicos de actuación. El primero tiene que ver con las campañas de propaganda (en general, aunque no exclusivamente, destinadas a hacer pedagogía entre los conductores y los ciudadanos en general). El segundo eje se refiere a la educación vial en la escuela (principalmente destinada a tratar de hacer pedagogía entre los niños $\mathrm{y}$ adolescentes, o sea, entre los futuros conductores). Finalmente, el tercer eje de actuación se refiere al diseño institucional propiamente dicho, a saber, a la actuación sobre las leyes y sobre sus instrumentos de aplicación. Pese a que estos tres ejes no siempre son nítidamente diferenciables, merece la pena tener en mente esta clasificación.

En este trabajo se realizará un repaso de los cambios producidos en la política de seguridad vial en España desde 2004 en lo referido a esa tercera

${ }^{5}$ El amplio margen de variación en las cifras se debe a que en el 2003 aún no era obligatorio realizarle las pruebas de alcoholemia a los fallecidos en accidentes de tráfico. Por su parte, Tortosa (2008) sitúa esa cifra entre un 30\% y un 50\%, y Villalba (2008) entre un 35\% y un $40 \%$. 
dimensión. Dada su importancia en la accidentalidad, el alcohol y la velocidad han sido el objeto principal de las reformas llevadas a cabo en los últimos años, y, del mismo modo, serán también uno de los principales ejes vertebradores en torno a los cuales se organizará este trabajo. En lo que sigue, en primer lugar se tratará de esbozar un retrato general de la política de seguridad vial en España antes de las reformas para posteriormente describir las características más destacables de las mismas. Se pondrá el acento principalmente en la reforma de la Ley de Tráfico y Seguridad Vial que introdujo los cursos de reeducación vial y el nuevo sistema de carné por puntos, en la reforma del Código Penal de 2007, y en los principales instrumentos que se están poniendo en funcionamiento para garantizar su aplicación: de manera destacada la extensión de las cámaras de control de la velocidad y de los controles de alcoholemia.

\section{La política de seguridad vial en España antes de las últimas reformas}

\subsection{La progresiva concienciación de estar ante un problema}

La primera legislación en materia de tráfico de vehículos a motor que se introdujo en España data del $1890^{6}$. Se trataba del Reglamento para el Servicio de Coches Automóviles por las Carreteras del Estado. Dicho reglamento limitaba la velocidad de circulación a $28 \mathrm{~km} / \mathrm{h}$ en carretera y $15 \mathrm{~km} / \mathrm{h}$ en ciudad y obligaba a matricular los vehículos (Montoro, 2003, Vargas, 2007).

Durante las primeras décadas del siglo XX se aprobaron muchas otras reglas, siendo la más importante de todas ellas el Código de la Circulación, de 25 de septiembre de 1934. Dicho código marcó la regulación subsiguiente, unificó las regulaciones anteriores y se convirtió en la norma más longeva que ha existido en España en materia de tráfico (Montoro, 2003, Vargas, 2007). De hecho, algunos de sus artículos han estado vigentes hasta la reforma de la Ley de Tráfico del año 2009. Por su parte, la primera regulación penal vino de la mano de la reforma del Código Penal de 1928 que, por primera vez, introdujo algunos artículos referidos al tráfico y la circulación (Vargas 2007).

Pese a esa temprana regulación, a lo largo de la práctica totalidad del siglo XX en España la seguridad vial no se consideró un problema serio. En lo que se refiere a los ciudadanos, las encuestas nunca mostraron que la seguridad vial fuese percibida como un problema importante ${ }^{7}$. Por lo que respec-

\footnotetext{
${ }^{6}$ Ésta fue la primera regulación moderna, la primera referida a los automóviles a motor. No obstante, las primeras regulaciones de la circulación en general son, obviamente, muy anteriores. Las más antiguas aplicadas en lo que hoy constituye el territorio del Estado Español datan de la época del Imperio Romano. Sobre estas cuestiones véase el citado Montoro (2003).

${ }^{7}$ Véanse, por ejemplo, los resultados de diferentes encuestas del CIS sobre la percepción de los españoles acerca de cuáles eran los principales problemas de España.
} 
ta a los representantes políticos, estos en pocas ocasiones mostraban una preocupación demasiado seria por el tema en sus declaraciones públicas y a nivel legislativo la inacción fue la tónica a lo largo de la mayor parte del siglo. Durante los años 80, en la primera etapa de la recuperación de la democracia, el elevado número de víctimas en accidentes de tráfico era visto generalmente como el (asumible) precio a pagar por la modernización del país y por la mejora de la calidad de vida (Thorson, 2008). Durante la transición y los primeros años de la democracia la política de seguridad vial en España fue prácticamente inexistente (Domènech, 2008). No se trataba simplemente de que los recursos destinados a este tema (y en consecuencia las medidas implementadas) fuesen insuficientes sino que en no pocas ocasiones las medidas aplicadas eran, en el mejor de los casos, erráticas y contradictorias. Un ejemplo servirá de ilustración. La aprobación de la Constitución supuso que todas las sanciones (incluidas las administrativas) tuviesen que ser fruto de una ley orgánica. Dicha decisión tuvo importantes repercusiones en materia de tráfico y seguridad vial ya que dejaron de tener efecto todas las sanciones del anterior código de circulación que sólo estaba aprobado por decreto y no por ley. De ese modo, durante años, cualquiera a quien se le impusiese una multa de tráfico tenía la posibilidad de recurrirla y de ganar el recurso de manera prácticamente automática. Dicha anomalía no se subsanó (y tan sólo parcialmente) hasta la modificación de la Ley de Tráfico en el año 1990 (Thorson, 2008).

Obviamente, resulta difícil, y probablemente carente de sentido, tratar de establecer de modo exacto las fechas en las que esta situación empieza a cambiar, aunque parece plausible sostener que ya a principios de los 90 empieza a percibirse la gravedad de la situación y el hecho de que se está ante un problema sobre el que es posible intervenir políticamente y no ante la consecuencia "natural" e inevitable de la modernización. En este sentido, en 1993 se alcanzó el record histórico de víctimas en accidentes de tráfico con un total de 4653 fallecidos en todo el Estado (Mena, 2007). A lo largo de los años 90 se producen algunas reformas legislativas remarcables y, a grandes rasgos, parece que podría sostenerse que entre los últimos años del siglo XX y los primeros del XXI la seguridad vial pasa a ser percibida definitivamente como un problema importante en España y se empieza a tratar de aplicar una política activa y coherente ${ }^{8}$. No obstante, tal y como se argumentará en el siguiente apartado, el salto adelante cualitativo se dará a partir de 2004 (Domènech, 2008, Thorson, 2008).

Los especialistas apuntan hacia la existencia de diferentes hitos importantes en este proceso.

Gran parte de la iniciativa en este sentido proviene de la Unión Europea (Domènech, 2008). En el año 1997 se celebró un pleno monográfico sobre

${ }^{8}$ Domènech (2008), Jané (2008), Pumpido (2007), Thorson (2008), Vargas (2007). 
accidentes de tráfico en el Parlamento Europeo. El pleno instó a la Comisión a que ésta a su vez instase a los Estados miembros a aplicar medidas tendentes a reducir el número de accidentes. Dicha iniciativa dio lugar, entre otros, al Libro Blanco del Transporte de 2001 y al Programa de Acción Europeo de Seguridad Vial de 2003, en los que se fijaba el objetivo de reducir en un 50\% el número de muertos de cara al 2010 (pasar de 50.000 a 25.000 muertos anuales) ${ }^{9}$.

Otro factor relevante en el caso español ha sido, según los expertos, la influencia ejercida por las políticas aplicadas en Francia (Thorson, 2008). La seguridad vial ya era un tema central del debate político en el país vecino a finales de los 80. La legislación francesa en materia de tráfico y seguridad vial es, en general, muy severa (Cardenal, 2008) y este fue uno de los primeros países de la Unión en los que se aplicó el denominado carné por puntos (Cremades \& Calvo-Sotelo Abogados, 2006).

Una tercera fuente de influencia sobre la política española de seguridad vial proviene del interior del propio Estado, concretamente desde Catalunya (Thorson, 2008). Los sucesivos Consellers y Conselleres de Interior han ido dando mayor importancia a la seguridad vial desde que en 1986, bajo el mandato del Conseller Pomés, se pusiesen las bases de lo que hoy es el Servei Català de Trànsit $(\mathrm{SCT})^{10}$. Las competencias en materia de seguridad vial se traspasaron a Catalunya en 1998. Desde entonces, los sucesivos gobiernos han dado un fuerte impulso a la política de seguridad vial dentro del marco de sus competencias. Dicho impulso se ha acelerado en los últimos años con la llegada al gobierno de la Generalitat (y a las Conselleries de Interior) del Govern d'Entesa. Entre otras cosas, cabe destacar la aprobación de los sucesivos Plans Integrals contra la Velocitat Excesiva (PIVE), de los Plans Catalans de Seguretat Viària o de la Llei de Mobilitat, una de las más avanzadas de Europa (Thorson, 2008). De manera muy destacada, el Pla Català de Seguretat Viària 2002-2004 planteó la necesidad de mejorar la seguridad vial de forma cuantificable. Concretamente, se estableció el objetivo de reducir el número de muertos y heridos graves respecto del año 2000. Esta fue la primera vez que en el territorio del Estado se fijaba un objetivo cuantificable en

\footnotetext{
${ }^{9}$ Véanse también la Carta Europea de Seguridad Vial; la Recomendación 2004/345/CE de la Comisión de 6 de abril de 2004, sobre la aplicación de las normas de seguridad vial (DO L 111 de 17.4.2004); así como la Recomendación 2001/115/CE de la Comisión de 17 de enero de 2001, sobre la tasa máxima de alcoholemia permitida para los conductores de vehículos a motor (DO L 43 de 14.2.2001). Por otra parte, uno de los documentos que más ha influido sobre la política europea de seguridad vial es el Informe del Grupo de Expertos de Alto Nivel para una Política Europea de Seguridad Vial, más comúnmente conocido como Informe Gerondeau.

${ }^{10}$ El SCT es el organismo responsable de la política de seguridad vial en Catalunya. Fue oficialmente constituido en 1998, bajo mandato del President Pujol.
} 
relación con esta materia y, de hecho, el gobierno central presionó para que fuese retirado sin conseguirlo (Thorson, 2008).

Así pues, paulatinamente en España se fue percibiendo que la inseguridad vial constituía un problema sobre el que se podía actuar políticamente (Domènech, 2008). A lo largo de los últimos años la regulación ha ido abarcando más y más aspectos de la circulación y las penas y controles se han ido tornando más estrictos y severos. En este sentido, cabe destacar una creciente intervención y severidad del derecho penal en la materia (Vargas, 2008, Villalba, 2008). El año 1995 se produjo una modificación el Código Penal que tipificaba como delitos la conducción bajo los efectos del alcohol o de substancias psicotrópicas, drogas tóxicas o estupefacientes, negarse a someterse a las pruebas para la detección de las sustancias anteriores, la conducción con temeridad manifiesta, la conducción con consciente desprecio por la vida de los demás y la creación de graves riesgos para la seguridad del tráfico (Perona, 2008). En el año 2000 se creó una subcomisión de seguridad vial y prevención de accidentes de tráfico en el Congreso de los Diputados. Entre los años 2000 y 2003 se acometieron diversos cambios legislativos como, por ejemplo, la modificación del Código de Circulación o la de la Ley de Tráfico. Sin embargo, entre todos ellos destaca la nueva modificación del Código Penal del año 2003 que trató de enfrentar los problemas más importantes en el ámbito del tráfico y la seguridad vial. No obstante, no parece exagerado argumentar que dicha reforma fue un fracaso (Navarro, 2008, Thorson, 2008). A continuación se repasarán las principales características de la legislación sobre seguridad vial el año 2003 y de los instrumentos para su aplicación.

\subsection{Año 2003: el agotamiento de un modelo}

Desde el año 1928 en el que, como se ha dicho más arriba, por primera vez se incorporaron al Código Penal algunos delitos relacionados con la seguridad en el tráfico, existe en España un modelo mixto administrativopenal de regulación de la seguridad vial. Las infracciones más graves, teóricamente, se abordaban por la vía penal y el resto por la administrativa (Vargas, 2007, Villalba, 2008). No obstante, lo anterior era sólo en teoría. Las reformas anteriores del Código Penal, en especial la de 2003, habían dado lugar a una gran ambigüedad en la distinción entre delito y falta que dejaba un amplio margen de discrecionalidad a los operadores jurídicos ${ }^{11}$. En general, el problema no era tanto que la ley no ofreciese instrumentos para sancionar de manera adecuada las conductas incívicas al volante sino que no se definían con precisión los distintos ilícitos (Corcoy, 2007, 2008, Navarro,

${ }^{11}$ González (2007), González y Vidales (2008), Hortal (2008), Jané (2008), Navarro (2008), Ulla (2008). 
2008). Existían numerosas cláusulas pendientes de valoración como las que hacían referencia al "exceso desproporcionado de velocidad", a la conducción "bajo la influencia del alcohol", o a los conceptos de "temeridad" o de "consciente desprecio por la vida de los demás", y se daba una total ausencia de límites claros en lo referido al alcohol, las drogas y la velocidad. En este sentido, resultaba sintomático encontrar calificaciones de la temeridad como si se tratara de un hecho y no de concepto jurídico pendiente de valoración. Obviamente, un problema derivado de estas indeterminaciones era la gran disparidad de criterios y la consecuente inseguridad jurídica que caracterizaba al conjunto del sistema (Moreno, 2008, Salom, 2008, Villalba, 2008).

Además del gravísimo problema de la indeterminación, otros serios problemas del sistema eran la existencia de numerosas contradicciones, como las que llevaban a que en numerosas ocasiones la sanción administrativa fuese más severa que la penal (Villalba, 2008), o la ausencia de tratamiento penal para la conducción sin carné o con el carné retirado así como para los quebrantamientos de condena en general (Ledesma, 2008). Este último hecho abría la puerta a un grave fenómeno de multireincidencia. En este sentido, muchos de los condenados por delitos contra la seguridad vial ya habían sido condenados en otras ocasiones (Corcoy, 2007, 2008).

Una consecuencia directa de la indeterminación de la regulación era que la práctica totalidad de las infracciones en este ámbito se clasificasen como faltas de modo que, salvo excepciones, el recurso a la vía penal resultaba poco menos que anecdótico ${ }^{12}$. En este sentido, algunos autores han señalado que se producía una utilización fraudulenta de la distinción entre delito y falta (Corcoy, 2007, 2008). Tal vez esto pueda resultar sorprendente. Resulta intuitivamente lógico que la indeterminación dé lugar a una amplia variedad de criterios y a condenas muy dispares para unos mismos hechos con la subsiguiente inseguridad jurídica. Pero tal vez no resulte inmediatamente tan evidente por qué la indeterminación tendría que llevar a que los ilícitos en esta materia fuesen prácticamente siempre castigados con las mínimas penas e incluso que en una gran cantidad de ocasiones resultasen impunes. Existen numerosos mecanismos que pueden dar cuenta de este hecho.

Corcoy $(2007,2008)$ apunta a que en la mayoría de casos el único interés de las víctimas y de los abogados de las compañías aseguradoras es que se satisfaga la responsabilidad civil. De este modo, los mismos abogados de las compañías presionan para que los casos se deriven a la vía administrativa. Además, dichos letrados no son penalistas y tratan de asegurar que los

12 Cano (2008), Campo (2008), Corcoy (2007, 2008), Domènech (2008), González (2007), González y Vidales (2008), Jané (2008), Mena (2007), Moreno (2008), Navaro (2008), Orts (2007), Perona (2008), Pumpido (2007), Salom (2008), Thorson (2008), Ulla (2008), Vargas (2007) y Villalba (2008). 
procesos sean lo más simples posible. Por otra parte, cabe tener muy en cuenta que dichos letrados no sólo, ni principalmente, defienden los intereses de las víctimas sino también y principalmente los de las compañías. Las compañías en unas ocasiones representarán a las víctimas pero en otras a los acusados de modo que les interesa que, en todo caso, las penas impuestas sean mínimas. En este sentido, numerosos autores sostienen que se había producido una mercantilización o privatización de la justicia en lo referente al tráfico y la seguridad vial en la que la prioridad había pasado a ser la obtención de una buena recompensa económica por parte de la víctima quedando relegada la necesidad de impartir justicia ${ }^{13}$. Según Pumpido (2007) en España se había pasado de un modelo de la "responsabilidad" a uno de "seguro" que confiaba a la composición privada y a las compañías aseguradoras la respuesta a la siniestralidad vial con debilitamiento de las obligaciones de los conductores. Nótese que existe una consecuencia especialmente perversa de este hecho. Una vez alcanzado el acuerdo entre las compañías aseguradoras la indemnización la paga la compañía. De modo que, en la mayoría de ocasiones toda la pena que debía enfrentar el infractor era un aumento en la cuota anual del seguro de su vehículo (Campo, 2008). En definitiva, se había llegado a una despenalización de facto de los delitos contra la seguridad vial (Pumpido, 2007).

Dicho modelo de "seguro" presentaba un segundo efecto perverso que merece la pena destacar. Cuanto más grave era la infracción cometida más probable resultaba que no fuese perseguida ni tan sólo a través de procedimiento de faltas. Como es bien sabido, las compañías aseguradoras pagan más rápidamente cuanto más probable es que su cliente sea condenado y cuanto mayor es la cuantía de la sanción que podría llegar aplicarse, o sea, cuanto más grave haya sido la infracción cometida. Por otra parte, para poder iniciar un procedimiento por faltas es necesario que la víctima presente una denuncia. De este modo, en los casos más graves solían producirse con mayor facilidad acuerdos entre las partes en los que la compañía aseguradora pagaba rápidamente y la víctima renunciaba a presentar denuncia. Así pues, paradójicamente, cuanto más grave era la infracción más probable resultaba que ésta no fuese perseguida (Salom, 2008) ${ }^{14}$.

Por otra parte, aun cuando se llega a juicio de faltas, es necesario recordar que en este tipo de procedimientos el fiscal acostumbra a estar ausente de manera que el peso de la acusación queda en manos del abogado de la víctima quien, una vez más, suele estar preocupado exclusivamente por la satisfacción de la responsabilidad civil (Campo, 2008, Salom, 2008). El mecanis-

${ }^{13}$ Corcoy (2007, 2008), González (2007), González y Vidales (2008), Mena (2007), Pumpido (2007), Salom (2008), Vargas (2007).

${ }^{14}$ Una segunda versión del mismo fenómeno se producía cuando la víctima presentaba denuncia pero posteriormente (tras llegar a un acuerdo económico) optaba por perdonar formalmente al acusado. 
mo que explica la dejación de las responsabilidades por parte de los fiscales en este tipo de procedimientos resulta bastante evidente, la saturación del sistema de justicia en España impide que los fiscales puedan hacer frente a todas sus responsabilidades cosa que los lleva a dejar de lado las cuestiones consideradas de menor importancia (Salom, 2008). En el pasado el Fiscal tenía que asistir a todos los juicios de faltas por imprudencia en la circulación viaria. No obstante, en 1992 el ejecutivo de Felipe González modificó la ley con la finalidad de descargar de trabajo a la Fiscalía. A partir de entonces el Fiscal ya sólo tiene que asistir a este tipo de procedimientos si es expresamente citado. En la práctica no lo es nunca (Salom, 2008). Éste es un ejemplo más de la ausencia de una orientación clara en la política de seguridad vial durante los años 80 y buena parte de los 90 .

Junto a los intereses de las compañías aseguradoras y de sus abogados, numerosos autores apuntan también a la actuación rutinaria de los jueces de instrucción y de lo penal, así como de los fiscales, que tipificaban mecánicamente como falta todas las infracciones sin plantearse las posibilidades de abrir un proceso penal (Corcoy, 2007, 2008, Salom, 2008).

Otros autores apuntan hacia el hecho de que la práctica totalidad de los operadores jurídicos son conductores. De este modo, acostumbran a mostrarse comprensivos con los acusados de haber infringido las reglas del tráfico dado que, en la mayoría de ocasiones, se trata de conductas en las que podrían haber incurrido ellos mismos u otras personas de su entorno social. Este tipo de empatía no se da, por ejemplo, en los casos de delitos contra la propiedad $^{15}$. Tal y como sostiene González (2007), así como en muchos ámbitos los legisladores y operadores jurídicos, y la mayoría de ciudadanos, tienden a empatizar con la víctima, esto no suele (o solía) ser así en el caso de las infracciones de las reglas de tráfico. En estos casos puede que se identifiquen con las víctimas, pero también resulta probable que lo hagan con los infractores. Al fin y al cabo, la mayoría de ciudadanos son también conductores y es probable que en determinadas ocasiones incumplan las normas de tráfico, pero son reacios a percibirse a ellos mismos como delincuentes por este hecho.

Además, en las escasas ocasiones en las que se tipificaba como delito y se condenaba a penas de prisión, éstas solían ser siempre inferiores a dos años (de las denominadas de "no cumplimiento") de modo que se suspendían de forma automática sin sustituirlas por penas alternativas ${ }^{16}$.

En resumen, para el año 2004 ya resultaba evidente que la reforma del Código Penal de 2003 había sido un fracaso y que era incapaz de hacer frente a los problemas a los que debía enfrentarse, mientras el derecho adminis-

${ }^{15}$ González (2007), González y Vidales (2008), Mena (2007), Mir (2008), Orts (2007), Thorson (2008).

${ }^{16}$ Corcoy (2007, 2008), González (2007), González y Vidales (2008). 
trativo resultaba a todas luces insuficiente para lidiar con las conductas más graves (Cano, 2008). De este modo, la sensación de impunidad continuaba aumentando entre la ciudadanía ${ }^{17}$.

Hasta aquí se han repasado de forma genérica los principales problemas de la legislación antes de las reformas. A continuación, también brevemente, se repasarán los problemas más específicos de lo que acabaron constituyendo los principales ejes de las reformas posteriores.

\subsubsection{El TRATAMIENTO DEL ALCOHOL Y LA VELOCIDAD}

El tratamiento del alcohol en la legislación española es de carácter mixto desde hace más de cuarenta años. En teoría, los casos más graves se tratan por vía penal y el esto por vía administrativa (Villalba, 2008).

El primer tratamiento administrativo del alcohol en la conducción de vehículos a motor vino de la mano de la Ley del Automóvil del año 1950 (Vargas, 2007, Villalba, 2008). La conducta típica era conducir "bajo la influencia de bebidas alcohólicas, drogas tóxicas o estupefacientes que colocaran al sujeto en un estado de incapacidad para realizarlo con seguridad". Se hacía por tanto referencia al hecho subjetivo de que el alcohol afectase a las capacidades del sujeto y no a la tasa objetiva de alcohol en sangre o en aire respirado. Este hecho hacía especialmente difícil demostrar que el la culpabilidad del sujeto. No se trataba sólo de demostrar que el individuo en cuestión había bebido sino que además había que demostrar que el alcohol afectaba a sus capacidades y que lo hacía en un grado tal que le impedía conducir con seguridad. En ese sentido, la legislación española se apartaba de la legislación europea del momento que tendía a hacer referencia a tasas de alcohol concretas (Gómez, 1998: 128 y ss., Vargas, 2007).

La ley de seguridad vial de 1990 supuso un salto adelante cualitativo en el tratamiento administrativo de la conducción ebria. Por primera vez se fijaron unas tasas máximas de alcohol en sangre así como sistemas de control y verificación de las mismas (Villalba, 2008). Desde entonces, las sucesivas reformas de la Ley de Seguridad Vial y del reglamento de circulación han ido reduciendo las tasas de alcohol permitidas y aumentando las sanciones a imponer. No obstante, eso no había sido así a nivel penal hasta la reforma de 2007 (Villalba, 2008).

A nivel penal, la conducción ebria se incorpora al Código Penal en 1963 instaurándose así el mencionado sistema mixto (Vargas, 2007, Villalba, 2008). Esta reforma seguía la línea de la reforma de la Ley del Automóvil de 1962 en el sentido de tender a una mayor objetivación de los ilícitos. No obstante, diversas sentencias del Tribunal Supremo a lo largo de los años 70 y la reforma del Código Penal de 1980 supusieron un nuevo retroceso al volver a

${ }^{17}$ Corcoy (2007, 2008), Thorson (2008), Villalba (2008). 
exigirse en el artículo 327 que la ingesta de alcohol afecte a la capacidad del sujeto para conducir "de modo que le impida hacerlo con seguridad" (Vargas, 2007).

Finalmente, las reformas del Código penal del 1995 y del 2003 también mantuvieron esa misma fórmula típica. Concretamente, el redactado de 2003 rezaba:

«El que condujere un vehículo de motor o ciclomotor bajo la influencia de drogas tóxicas, estupefacientes, sustancias psicotrópicas o de bebidas alcohólicas será castigado con la pena de prisión de tres a seis meses o a la de multa de seis a doce meses y, en su caso, trabajos en beneficio de la comunidad de treinta y uno a noventa días y, en cualquier caso, privación del derecho a conducir vehículos a motor y ciclomotores por tiempo superior a uno y hasta cuatro años».

En cada caso era necesario determinar si el individuo había consumido alcohol, si dicho consumo hacía que se encontrase o no "bajo los efectos" de bebidas alcohólicas y qué podía considerarse una "alta tasa" de alcohol en sangre. De este modo, tal y como se ha mencionado más arriba, la indeterminación de la fórmula escogida acabó llevando a que la calificación y condena penal de la conducción ebria resultase poco menos que anecdótica ${ }^{18}$.

Por lo que se refiere a la velocidad, a diferencia del alcohol, ésta había tenido un tratamiento exclusivamente administrativo hasta la reforma de $2007^{19}$. La sanción máxima por exceso de velocidad era de 600 euros y la suspensión del permiso de conducción por un máximo de tres meses. A la práctica, la sanción estándar que solía imponerse de manera rutinaria era una multa de 300 euros (Thorson, 2008). Así pues, la práctica totalidad de los denominados "conductores bala" que eran descubiertos conduciendo sus vehículos a velocidades de 220 o $250 \mathrm{~km} / \mathrm{h}$ eran sancionados exclusivamente con una multa económica, con la consecuente alarma social y sensación de impunidad generadas (Navarro, 2008).

\subsubsection{LA CONDUCCIÓN CON TEMERIDAD MANIFIESTA}

El antiguo artículo 381 del Código Penal era (junto al 384) uno de los dos artículos destinados a tratar la conducción temeraria. El artículo 381 se destinaba, concretamente, a la conducción con temeridad manifiesta y su redactado rezaba:

${ }^{18}$ González (2007), González y Vidales (2008), Hortal (2008), Mena (2007), Pumpido (2007), Villalba (2008).

${ }^{19}$ A excepción de los casos en que ésta pudiese constituir temeridad manifiesta. Se aborda esta cuestión a continuación. 
«El que condujere un vehículo a motor o un ciclomotor con temeridad manifiesta y pusiere en concreto peligro la vida o la integridad de las personas será castigado con las penas de prisión de seis meses a dos años y privación del derecho a conducir vehículos a motor y ciclomotores por tiempo superior a uno y hasta seis años».

Una vez más podemos observar la ambigüedad y falta de concreción en el redactado (Hortal, 2008). Es sintomático, como se ha mencionado anteriormente, encontrar calificaciones de la temeridad como si se tratara de un hecho y no de un jurídico pendiente de valoración. En este caso además, una segunda dificultad proviene de la necesidad de probar la existencia de un peligro concreto. Estos problemas acabaron conduciendo a que prácticamente nunca se condenase por este supuesto en ausencia de resultados lesivos (Moreno, 2008, Salom, 2008).

Con la reforma de 2003 se le añadió un segundo párrafo de modo que el redactado definitivo acabó siendo:

«El que condujere un vehículo a motor o un ciclomotor con temeridad manifiesta y pusiere en concreto peligro la vida o la integridad de las personas será castigado con las penas de prisión de seis meses a dos años y privación del derecho a conducir vehículos a motor y ciclomotores por tiempo superior a uno y hasta seis años.

En todo caso, se considerará que existe temeridad manifiesta y concreto peligro para la vida o la integridad de las personas en los

${ }^{20}$ La propuesta de CIU rezaba:

"El que condujere un vehículo a motor o un ciclomotor con temeridad manifiesta y pusiere en concreto peligro la vida o la integridad física de las personas, será castigado con las penas de prisión de uno a dos años y privación del derecho de conducir vehículos por tiempo superior a uno y hasta seis años.

La realización de la imprudencia grave del hecho previsto en el apartado anterior será castigada con la pena de prisión de seis meses a un año y privación del derecho de conducir por tiempo superior a uno y hasta cuatro años.

Existe temeridad manifiesta, a los efectos de los párrafos anteriores, entre otros casos, en el de quien condujere un vehículo a motor o un ciclomotor sobrepasando en más de un cincuenta por ciento la velocidad máxima autorizada, siempre que ello suponga superarla al menos en cincuenta kilómetros por hora.

Aunque no concurra un concreto peligro para la vida o la integridad de otras personas, el que condujere un vehículo a motor o un ciclomotor sobrepasando en más de un cincuenta por ciento la velocidad máxima autorizada, siempre que ello suponga superarla al menos en cincuenta kilómetros por hora, será castigado con la pena de prisión de tres a seis meses y de privación del derecho de conducir por tiempo superior a uno y hasta cuatro años.

JUSTIFICACIÓN

Necesidad de superar las dificultades en la interpretación de la actual redacción del artículo, así como de penalizar todas aquellas conductas peligrosas e imprudentes que atenten contra la seguridad del tránsito." (Moreno, 2008: 53). 
casos de conducción bajo los efectos de bebidas alcohólicas con altas tasas de alcohol en sangre y con un exceso desproporcionado de velocidad respecto de los límites establecidos».

Dicha reforma fue una solución de compromiso. Cuando se tramitó la reforma de 2003, el grupo de CIU en el Senado propuso una enmienda que pretendía ir en la misma línea en la que finalmente se fue con la reforma de $2007^{20}$. El Grupo Popular, entonces con mayoría absoluta en el Parlamento, adoptó una transacional que fue la que acabó plasmándose en el redactado definitivo y que se reconoció como una solución momentánea de compromiso (Moreno, 2008).

Con dicha reforma se pretendió crear un instrumento que permitiese facilitar la prueba de la presencia de un peligro concreto así como clasificar como delitos los ilícitos más graves relacionados con el alcohol y la velocidad al volante. No obstante, como se ha dicho, dada su indeterminación dicha reforma fracasó estrepitosamente en sus objetivos y el artículo continuó siendo inoperante en la práctica ${ }^{21}$.

En lo referente estrictamente al alcohol se daban exactamente los mismos problemas que en el caso del antiguo artículo 379, así que no se volverá a comentar. En lo que hace referencia a la velocidad es necesario destacar que la reforma de 2003 abrió por primera vez la puerta a condenar penalmente por este supuesto (Villalba, 2008). Es cierto que no se penaba el exceso de velocidad (o la velocidad inadecuada) per se, pero existía la posibilidad de condenar cuando éste supusiese una temeridad manifiesta. No obstante, una vez más, la falta de concreción acerca de lo que debía entenderse por exceso "desproporcionado" de velocidad condujo a que prácticamente nunca se condenase por este supuesto (Villalba, 2008) y a que la práctica totalidad de los denominados "conductores bala" que eran descubiertos conduciendo sus vehículos a velocidades cercanas a los $250 \mathrm{~km} / \mathrm{h}$ fuesen derivados a la vía administrativa de forma rutinaria (Navarro, 2008).

\subsubsection{LA CONDUCCIÓN CON CONSCIENTE DESPRECIO POR LA VIDA DE LOS DEMÁS}

El otro artículo del Código Penal de 1995 destinado a enfrentar el problema de la conducción temeraria era el 384. Concretamente dicho artículo se refería a la conducción con consciente desprecio por la vida de los demás y rezaba:

«Será castigado con las penas de prisión de uno a cuatro años, multa de seis a doce meses y privación del derecho a conducir vehículos a motor y ciclomotores por tiempo superior a seis y hasta

\footnotetext{
${ }^{21}$ Mena (2007), Moreno (2008), Navarro (2008), Pumpido (2007).
} 
diez años el que, con consciente desprecio por la vida de los demás, incurra en la conducta descrita en el artículo 381.

Cuando no se hubiere puesto en concreto peligro la vida o la integridad de las personas, las penas serán de prisión de uno a dos años, manteniéndose el resto de penas».

No obstante, este artículo volvió a encontrarse con los problemas generales ya mencionados, más algunos otros particulares. En primer lugar, nuevamente nos encontramos ante un caso de indeterminación, esta vez doble. Para condenar por este supuesto no sólo hay que superar la dificultad de discernir qué es una conducción temeraria sino también la de qué significa conducir "con consciente desprecio por la vida de los demás"22. Nótese que en este caso vuelve a utilizarse un término referido claramente a los estados mentales del sujeto: "consciente". O sea, no es suficiente con demostrar que un observador imparcial determinaría que la conducta en cuestión no respeta la vida de los demás, cosa que abriría la puerta a una mayor objetivación del tipo; sino que se requiere demostrar que el conductor despreciaba conscientemente la vida de los demás (Mena, 2007).

Todos estos problemas llevaron a que el artículo en cuestión resultase inoperante en la práctica ${ }^{23}$. Prácticamente sólo se usó para condenar en algunos casos de lo que vino a denominarse como conducción "suicida" u "homicida" ${ }^{24}$ (Orts, 2007), pero ni tan sólo en estos casos su uso fue general (Mena, 2007, Pumpido, 2007).

\subsubsection{LESIONES Y MUERTES}

Por lo que se refiere a las infracciones con resultado de lesiones o muertes, el antiguo artículo 382 del Código Penal de 1995 rezaba:

«Cuando con los actos sancionados en los artículos 379, 381 y 382 se ocasionara, además del riesgo prevenido, un resultado lesivo constitutivo de delito, cualquiera que sea su gravedad, los Jueces o Tribunales apreciarán tan sólo la infracción más gravemente penada, condenando, en todo caso, al resarcimiento de la responsabilidad civil que se haya originado.

\footnotetext{
${ }^{22}$ González (2007), González y Vidales (2008), Hortal (2008), Moreno (2008), Orts (2007).

${ }^{23}$ Boix, Orts, Vives (1989: 63 y ss.), González (2007), González y Vidales (2008), Orts (2007).

${ }^{24}$ A mediados de los 80 se dieron algunos casos de individuos que apostaban sobre si uno de ellos era capaz de conducir su vehículo a toda velocidad y en dirección contraria por la autopista. Pese a que los casos no fueron demasiado numerosos si que llegó a extenderse la percepción de que se trataba de una cierta moda y se creó una gran alarma social (Orts, 2007).
} 
En la aplicación de las penas establecidas en los citados artículos, procederán los jueces y tribunales según su prudente arbitrio, sin sujetarse a las reglas prescritas en el artículo 66».

En lo que estrictamente se refiere al redactado del artículo, cabe decir que la disposición según la cual los jueces no están sujetos a lo previsto por el artículo 66 suponía una nueva fuente de discrecionalidad y, de facto, también de suavización de las condenas. ${ }^{25}$

De modo general cabe destacar que las infracciones con resultado de lesiones y muertes eran una de las áreas en las que más claramente podía, y puede aún en una importante medida, apreciarse la falta de conciencia de encontrarse ante un problema importante por parte de los operadores jurídicos.

Un primer y claro ejemplo en este sentido viene dado por los casos en los que un conductor causa un accidente en el que mata a varias personas. Este tipo de casos suelen ser calificados como concursos ideales, es decir, se considera que sólo se ha cometido un sólo hecho. En cambio, ese criterio no se mantiene en otros casos, como por ejemplo las acciones terroristas, que suelen calificarse como concurso real de modo que se aplica una regla de acumulación (González, 2007, González y Vidales, 2008). La diferencia de criterio denota, una vez más, la percepción del operador jurídico de encontrarse ante un tipo de criminalidad que, como sostenían Bockelman y Göpinger en un texto clásico sobre la cuestión' "no es verdadera delincuencia dado que afecta a la gran mayoría de ciudadanos que se esfuerzan en vivir conforme a derecho" (citados en Mena, 2007: 126).

Otro ejemplo viene dado por el hecho de que las imprudencias (no sólo en el ámbito del tráfico) se clasificaban como leves de manera sistemática derivándose de manera rutinaria a procedimientos de faltas $\mathrm{y}$, como se ha dicho, convirtiendo de esa manera en inoperantes a los artículos 381 y 384 del antiguo Código Penal. Esto era así incluso en los casos en los que la imprudencia acarreaba muertes o lesiones ${ }^{26}$.

En la práctica, en muy pocas ocasiones se condenó penalmente por muertes o lesiones resultado de imprudencias temerarias (Corcoy, 2007, 2008). Algunas escasas excepciones en este sentido venían dadas por aquellos casos en los que el conductor sufría el accidente cuando huía de la policía o por los denominados "conductores suicidas" 27 . No deja de ser sintomático que sea precisamente en este tipo de casos en los que más se actuó a través de la vía penal. Precisamente se trata de conductas propias de colectivos marginales con los que difícilmente los operadores jurídicos pueden identificarse.

\footnotetext{
${ }^{25}$ Sobre esta cuestión véanse Hortal (2008) y Mena (2007).

${ }^{26}$ Corcoy (2007, 2008), González (2007), González y Vidales (2008).

${ }^{27}$ Corcoy (2007, 2008), Orts (2007), Salom (2008).
} 
Pero, tal y como se ha apuntado anteriormente, incluso en las pocas ocasiones que se condena por delito de homicidio o de lesiones graves por imprudencia grave o temeraria se imponían penas inferiores a los dos años de prisión, de las denominadas "de no cumplimiento". No obstante, cabe destacar que en principio en un homicidio por imprudencia grave se podían imponer penas de hasta cuatro años de cárcel. Nuevamente, las penas de prisión, en los pocos casos en que eran impuestas, eran suspendidas de forma prácticamente automática sin substituirlas por penas alternativas. Como en casos anteriores, dichas suspensiones automáticas en casos que podían haber generado una gran alarma social acarreaban una gran sensación de impunidad (Corcoy, 2007, 2008).

\subsubsection{LA CONDUCCIÓN SIN LICENCIA}

La reforma del Código penal de 1967 mencionada anteriormente incorporó al mismo el delito de conducción sin carné. Sin embargo, la reforma de 1983 suprimió dicho delito y lo relegó al ámbito administrativo ${ }^{28}$. Nos encontramos nuevamente aquí con la voluntad del ejecutivo de González de reducir la saturación del sistema de justicia a través de la despenalización de aquellas conductas consideradas de poca gravedad, así como con otro ejemplo de la ausencia de una política de seguridad vial clara y coherente durante aquel período (Thorson, 2008). La primera consecuencia de aquella decisión fue un espectacular aumento de los accidentes en los que estaban implicados conductores sin carné, un $1100 \%$ durante los cinco primeros años (Cano, 2008).

La conducción con el carné retirado o sin haberlo obtenido nunca no volvió completamente al Código Penal hasta la reforma de 2007. Antes de la reforma sólo se podía sancionar penalmente en el caso particular de que alguien condujese con el carné retirado por mandato judicial dado que el quebrantamiento de una resolución judicial ya era un delito. No obstante, también en el terreno del quebrantamiento de resoluciones judiciales existían problemas para condenar (sobre todo en el caso de las sanciones cautelares) ${ }^{29}$.

Así pues, hasta la última reforma la conducción si carné se sancionaba únicamente por vía administrativa. Dicha sanción consistía en una multa económica y en la prohibición de obtener el carné durante dos años. Una sanción de esa naturaleza resultaba a todas luces insuficiente y hasta contraproducente. En primer lugar, no parece que quien ya está conduciendo sin carné vaya a preocuparse demasiado porque le prohíban obtenerlo durante los

\footnotetext{
${ }^{28}$ Martínez (2008), González (2007), González y Vidales (2008), Thorson (2008).

${ }^{29}$ Véase González (2007) así como la propia Exposición de Motivos de la reforma de 2007.
} 
dos próximos años. En segundo lugar, la sanción económica tampoco parece demasiado disuasoria cuando el $70 \%$ de los condenados por conducir sin carné resultan ser insolventes (Ledesma, 2008).

Finalmente, uno de los problemas más graves para la protección jurídica de la seguridad vial era el de la multireincidencia. En muchas ocasiones los autores de las infracciones más graves ya habían sido condenados con anterioridad por este tipo de hechos y estaban privados del derecho a conducir o carecían de carné (Corcoy, 2007, 2008).

\subsection{Los instrumentos de aplicación de la legislación}

Obviamente, el conocimiento del diseño institucional de un Estado no consiste sólo en la lectura del redactado de sus leyes sino que requiere ir más allá y fijarse en cosas como su interpretación o sus posibilidades de aplicación (Cardenal, 2008).

Hasta ahora se ha hecho explícito como las leyes eran interpretadas de un modo tal que permitía aplicarlas de forma excesivamente suave, e incluso no aplicarlas. Se ha señalado también lo errático de la política de seguridad vial llevada a cabo en España durante muchos años así como la existencia de problemas endémicos como la falta de medios de la Justicia.

Sin embargo, a la hora de referirse a los instrumentos de aplicación de la legislación en materia de tráfico, es necesario poner el acento en el más importante de todos ellos: los dispositivos de control del cumplimiento, de modo muy especial, los controles de alcoholemia y los radares de medición de la velocidad.

En 2003, la extensión de estos dispositivos de control del alcohol y la velocidad eran, según los expertos, deficitaria ${ }^{30}$. Cabe destacar la extrema gravedad de este hecho ya que, obviamente, la ley será inútil sino existe una mínima certeza de que el incumplimiento puede ser descubierto y sancionado (Mir, 2008). Por lo que se refiere a la velocidad, la Dirección General de Tráfico no instaló el primer en España hasta 1994, y en 2004 era el Estado de la UE-15 con menos controles establecidos en las carreteras y menos sanciones impuestas por ese concepto. Por poner sólo un ejemplo, en ese año en España sólo se detectaron 25,2 sanciones por cada 1000 habitantes, mientras que en Holanda (un país con un índice de cumplimiento mucho más elevado y una accidentalidad mucho menor) la cifra llegó a las 850. En cuanto al alcohol, España se encontraba entre los 6 Estados de la UE-15 que menos controles por habitante realizaba (Perona, 2008).

${ }^{30}$ Domènech (2008), González (2007), González y Vidales (2008), Mir (2008), Perona (2008), Thorson (2008). 


\section{La política de seguridad vial entre el 2004 y el 2010}

Tal y como se ha comentado en la introducción, el cambio de gobierno de 2004 marca un cambio cualitativo en la política de seguridad vial en España (Domènech, 2008, Thorson, 2008). Pese a que la lista de cambios es muy larga, dos reformas sobresalen de manera especial sobre todas las demás: la modificación del año 2006 de la Ley de Tráfico y Seguridad Vial para dar cabida al carné por puntos y a los cursos de sensibilización, y la reforma del Código Penal del año 2007. Esos dos hitos se analizarán de manera especial en las dos primeras secciones de este apartado. En la tercera se revisarán de forma rápida otras modificaciones destacables. Este apartado, como el resto del trabajo, no tiene vocación de exhaustividad.

\subsection{La reforma de la Ley de tráfico y seguridad vial: el carné por puntos y los cursos de sensibilización ${ }^{31}$}

El carné por puntos «es una modalidad del permiso o licencia de conducción en la que los conductores cuentan con un saldo de puntos, de modo que las sanciones de tráfico que se les impongan llevan aparejadas la pérdida de algunos de esos puntos. Cuando el saldo quede a cero, el conductor pierde el carné y, consecuentemente, no podrá conducir. Por otra parte, el transcurso del tiempo sin ser sancionado se traduce en aumentos del saldo de puntos». (Cremades \& Calvo-Sotelo Abogados, 2006: 7).

El carné no substituye a la sanción económica y ni mucho menos, claro está, al posible tratamiento penal de las infracciones. Independientemente de aquéllas, cuando un conductor sea sancionado en firme por vía administrativa por la comisión de alguna infracción grave o muy grave se le descontarán automáticamente los puntos correspondientes a la misma.

El carné entró en vigor el 1 de julio de 2006. Dicho dispositivo tiene un doble objetivo. Por un lado se pretende penalizar la reincidencia en la violación de las normas de circulación. Por otra parte, pretende incentivar la constancia de los buenos conductores. Dicho de otro modo, se trata de crear una conciencia social favorable a la conducción cívica y de rechazo a las conductas incívicas.

El conjunto de la normativa pretende tener, en primer lugar, un carácter reeducador. Se trata de hacer consciente al conductor incívico de las consecuencias de su actitud para la vida y la integridad de las demás personas y para las suyas propias.

En segundo lugar, tal y como reza la exposición de motivos de la propia ley, la otorgación de puntos pretende ser un reflejo de la confianza que la

${ }^{31}$ Este apartado se basa, principalmente, en Cremades \& Calvo-Sotelo Abogados (2006) $\mathrm{y}$ en Thorson (2008). 
sociedad le concede al conductor mientras que su pérdida constituye un reproche por su conducta, por haber abusado de la confianza depositada en él. El carné por puntos puede entenderse como un contrato entre conductor y la sociedad. Se rompe con la lógica del derecho a conducir que, una vez obtenido, se mantiene de por vida. Si el conductor incumple su parte, el contrato se rompe. Dicha ruptura pretende suponer un reproche, no tanto por haber violado la ley sino más bien por la actitud reiterada de desprecio por la vida y la integridad física de los demás. La idea de falta de respeto continuada resulta importante aquí. De manera general, no se retira el carné a la primera infracción. Se define una escala. Tras una infracción se impone una multa, pero se puede continuar conduciendo. Pero si se sigue incumpliendo, llega un momento en que la sociedad, a través de sus instituciones, determina que dicho conductor es peligroso y que no está en condiciones de cumplir con los términos del contrato ${ }^{32}$.

En el momento de aplicarse la medida, los conductores que disponían de un permiso de conducir con una antigüedad de más de tres años partieron con un total de 12 puntos. Los que no alcanzaban esa antigüedad partieron con 8. Los conductores noveles en general parten con un saldo de 8 puntos. También es de 8 puntos el saldo inicial de los conductores que, tras haber perdido todos sus puntos, recuperan el permiso de conducir.

Según la gravedad de la infracción cometida, se pueden perder 2, 3,4 o 6 puntos. El siguiente cuadro recoge los tipos de infracciones que acarrean pérdida de puntos $^{33}$.

\footnotetext{
${ }^{32}$ Los conductores no perderán más de 8 puntos por acumulación de infracciones en un sólo día. No obstante, si se da acumulación y alguna de las infracciones es muy grave, entonces se perderá el número de puntos que corresponda. De este modo, en casos extremos es posible perder el carné de una sola vez.

${ }^{33}$ El proyecto de reforma de la Ley de Tráfico que, en el momento en que se está redactando este trabajo, se encuentra en el Senado, introduce algunas modificaciones mínimas en este punto. De aprobarse la reforma con el actual redactado, no se perderían puntos por estacionar en carriles destinados para el transporte público urbano y sólo se perderían puntos por superar el límite de velocidad en autopistas y autovías al sobrepasar los $151 \mathrm{~km} / \mathrm{h}$. Esto significa que, siempre que se circule a menos de $151 \mathrm{~km} / \mathrm{h}$, no se perderían puntos por superar en más de $20 \mathrm{~km} / \mathrm{h}$ los límites de velocidad en las autopistas y autovías reguladas por un sistema de velocidad variable como las entradas y salidas de Barcelona. Por otra parte, se intensifican las sanciones por otras infracciones como llevar inhibidores de radar. No obstante, pese a los cambios, la lógica básica del carné continúa siendo la misma.
} 


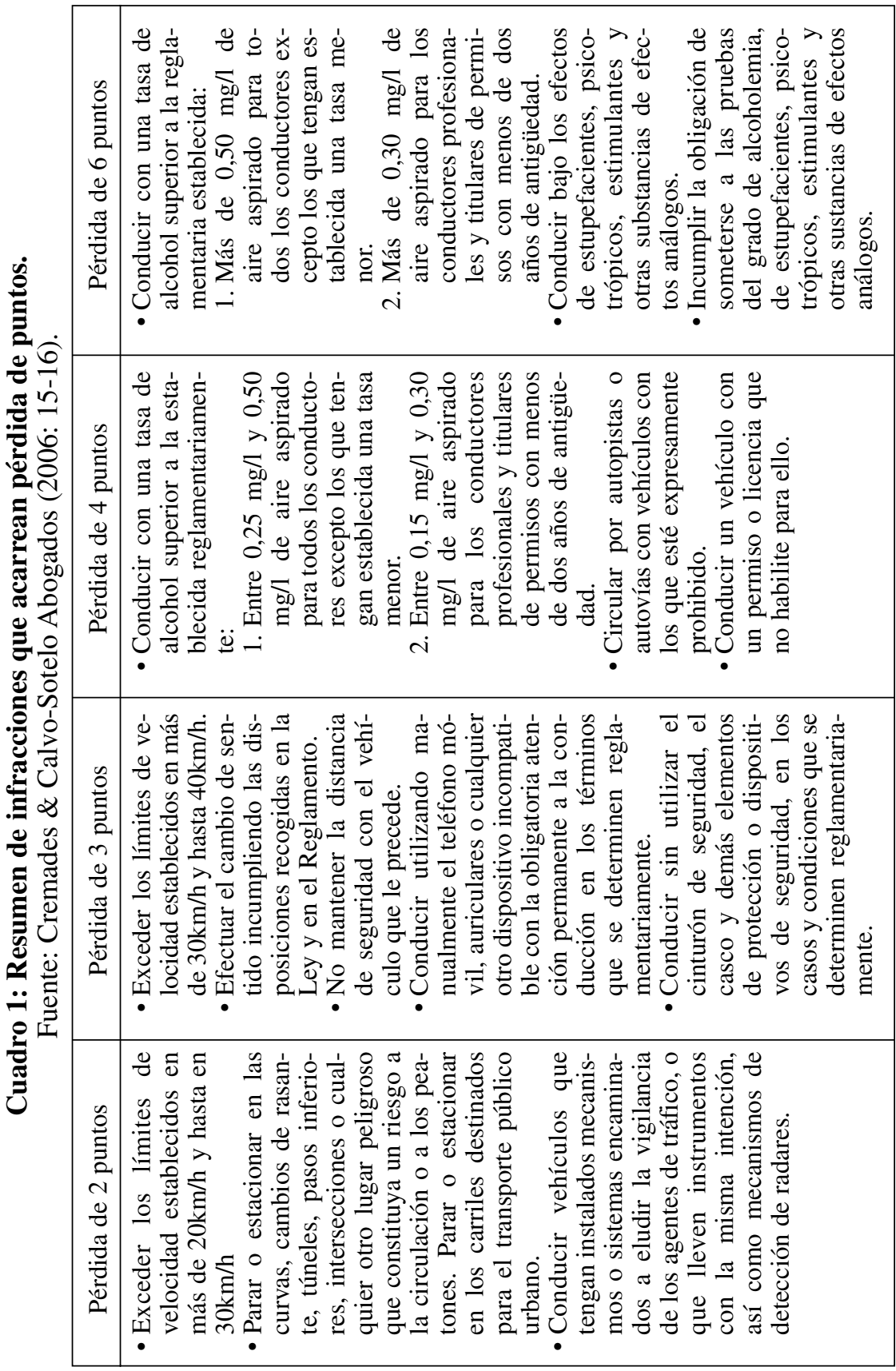




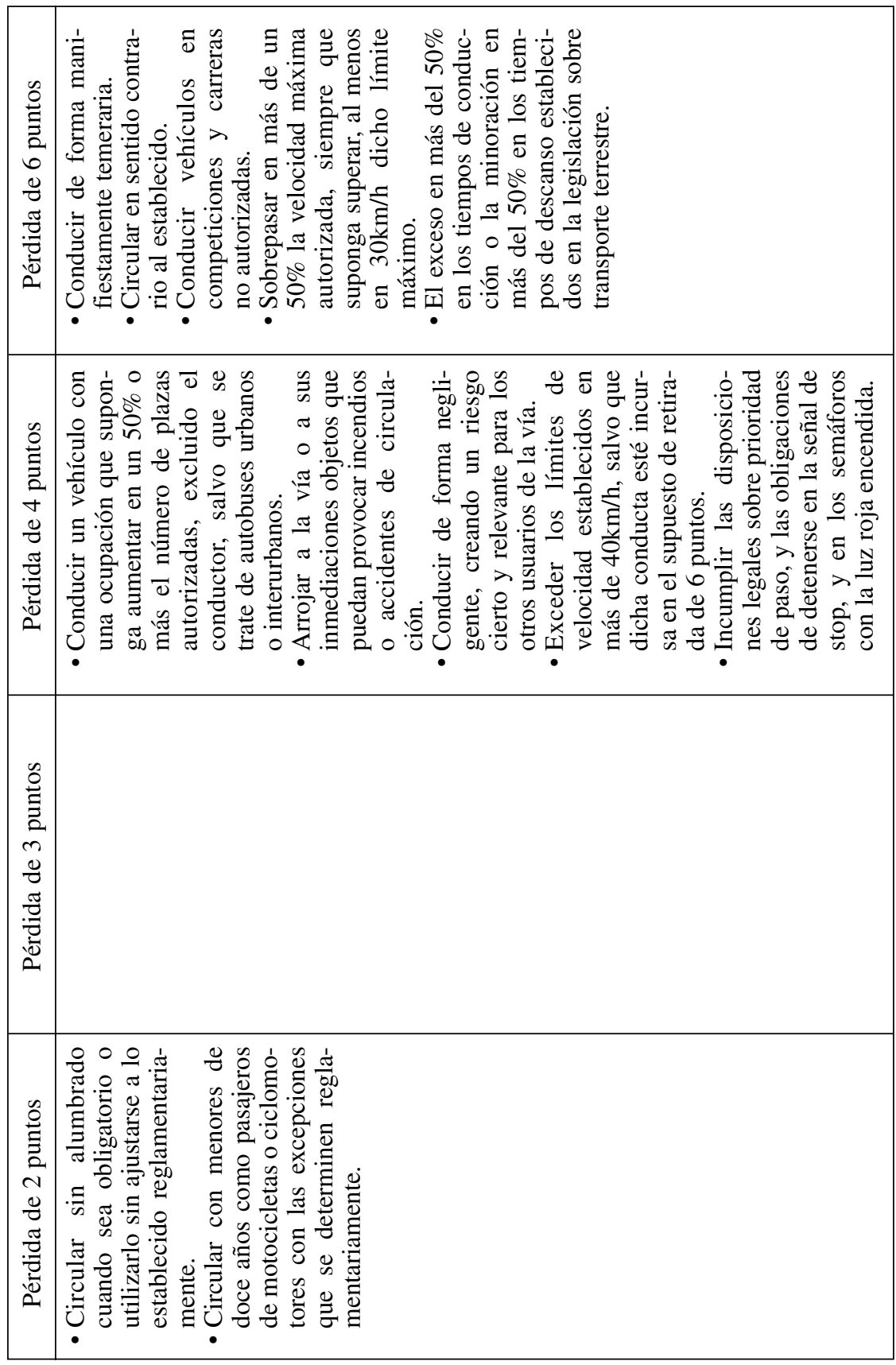




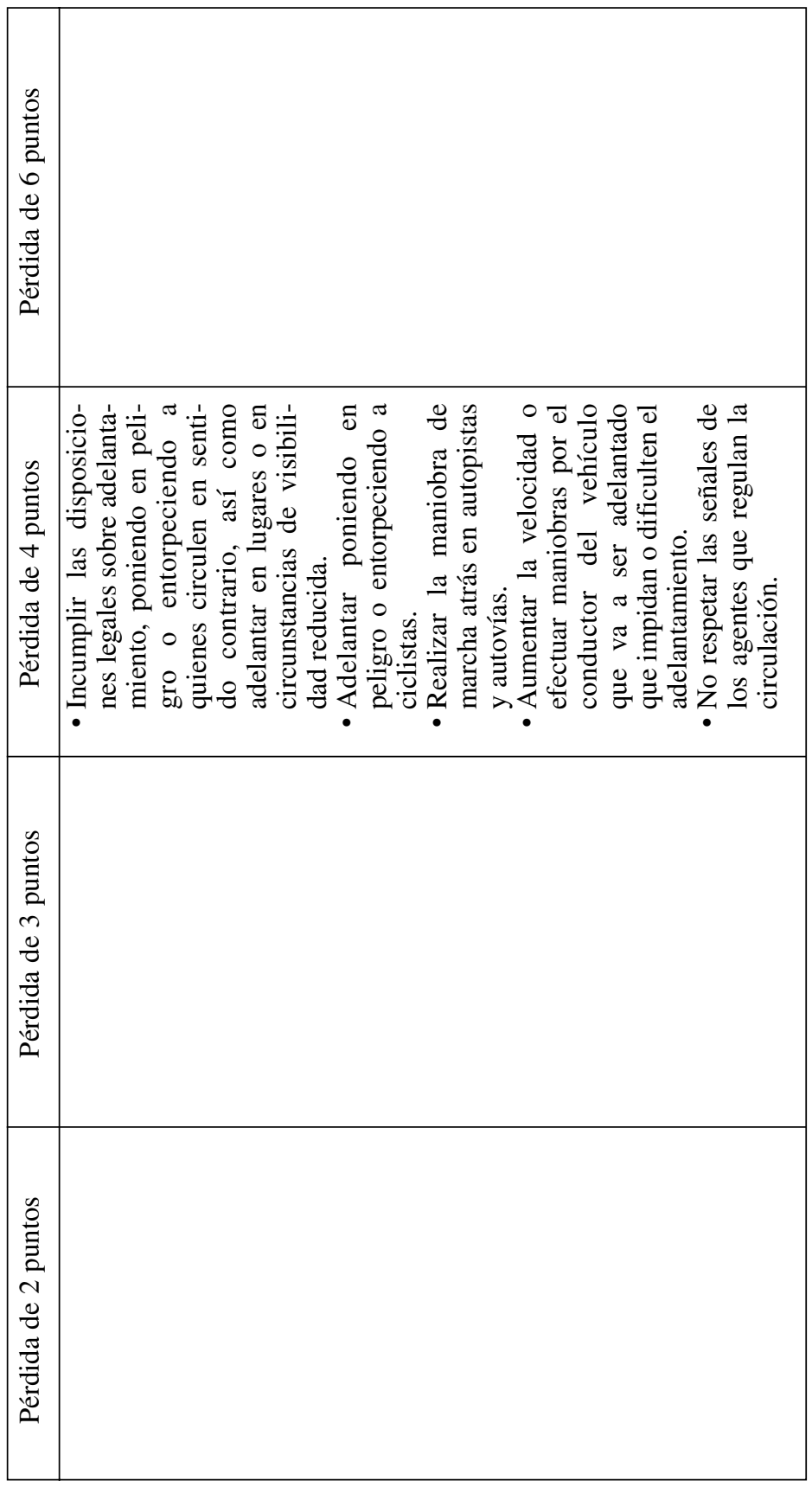


Una vez que se han perdido puntos, existen dos vías para recuperarlos. La primera es por el mero transcurso del tiempo sin cometer infracciones. La segunda consiste en realizar los cursos establecidos por el reglamento. Los conductores que hayan perdido parte de sus puntos podrán recuperarlos en su totalidad si transcurren dos años sin ser sancionados. No obstante, si alguno de los puntos se ha perdido por la comisión de infracciones muy graves, el plazo de tiempo para recuperarlos será de tres años. Por su parte, quienes, tras haberlo perdido, recuperen el carné con un saldo inicial de 8 puntos podrán recuperar el total de 12 si transcurren dos años sin que vuelvan a ser sancionados.

Por último, quienes conserven el carné sin haber perdido ningún punto, recibirán dos puntos extras durante los tres primeros años, y un punto más por los tres siguientes, pudiendo llegar a acumular un total de 15 puntos. De hecho, el pasado julio de 2009 se cumplieron tres años de la entrada en vigor del carné por puntos y varios millones de conductores fueron recompensados con dos puntos extra. Según la Dirección General de Tráfico, disponer de 15 puntos implica que el conductor que los posee se encuentra entre los mejores y conduce respetando su vida y la de los demás.

Un elemento esencial del nuevo sistema lo constituyen los cursos de reeducación vial. La realización y superación de dichos cursos permite la recuperación de un máximo de cuatro puntos sin que en ningún caso se puedan recuperar más puntos de los que se han perdido ${ }^{34}$. Sólo se permite la realización de estos cursos una vez cada dos años, de modo que sólo pueden recuperarse 4 puntos cada dos años ${ }^{35}$.

El siguiente cuadro resume el contenido de los cursos de sensibilización y reeducación vial.

\section{Cuadro 2: Resumen de los contenidos de los cursos de sensibilización y educación vial.}

Fuente: Elaboración propia a partir de Cremades \& Calvo-Sotelo Abogados (2006: 19-25).

1. Los accidentes de tráfico: la magnitud del problema.

a) Valorar la dimensión real de los accidentes de tráfico, los problemas sociales y económicos que se producen en su entorno.

b) Identificar el accidente de tráfico como un problema de salud y el conjunto de los siniestros, como una epidemia que nos afecta a todos.

${ }^{34} \mathrm{Si}$ se aprueba el texto de la reforma de la Ley de Tráfico mencionado más arriba podrán recuperarse un máximo de 6 puntos.

${ }^{35}$ Para el caso de los conductores profesionales la frecuencia podrá ser anual. 
c) Apreciar que los accidentes no son causa del azar o del destino, sino que detrás de ellos hay una serie de factores de riesgo sobre los que podemos actuar.

d) Reconocer que es el propio conductor el que más puede influir en la producción de accidentes.

e) Distinguir las principales variables del vehículo, de la vía y de su entorno que se relacionan con una mayor accidentalidad.

2. Dinámica de un impacto y consecuencias para las víctimas.

a) Comprender los conceptos generales sobre la dinámica de un accidente.

b) Apreciar la magnitud real de las fuerzas que se implican en los siniestros de tráfico.

c) Conocer los principales tipos de lesión que se producen en los accidentes.

d) Distinguir las lesiones que se pueden ocasionar en función del tipo de accidente (impacto frontal, lateral, alcance y vuelco).

e) Diferenciar las lesiones que suelen producirse según el tipo de vehículo implicado (automóviles de turismo, transportes ligeros y pesados, bicicletas y motocicletas).

f) Conocer las características de las lesiones que suele tener el peatón que ha sido atropellado.

3. La conducción: una tarea de toma de decisiones.

a) Apreciar que las situaciones peligrosas al volante son en muchas ocasiones consecuencia de decisiones incorrectas.

b) Distinguir las características del proceso de toma de decisiones en la conducción.

c) Discriminar cuáles son las actitudes y los motivos que diferencian a un conductor seguro de aquel que conduce de forma peligrosa.

d) Valorar el importante papel que puede jugar nuestro estado emocional en la seguridad del tráfico.

e) Identificar la influencia de la percepción y la aceptación del riesgo en la conducción.

f) Considerar la influencia que tienen sobre nuestro propio comportamiento las interpretaciones que hacemos del comportamiento de los demás.

4. Aptitudes y capacidades básicas para una conducción segura.

a) Apreciar la complejidad del entorno del tráfico.

b) Valorar la importancia de mantener tus aptitudes y capacidades básicas en perfectas condiciones para conducir.

c) Identificar la importancia del buen funcionamiento de tus sentidos, especialmente la vista, para conducir de forma segura.

d) Diferenciar el papel de los mecanismos atencionales en la conducción. 
e) Distinguir la incidencia de las distracciones en los accidentes de tráfico.

f) Identificar la importancia de las capacidades motoras para conducir con seguridad.

5. Los grupos de riesgo.

a) Apreciar que determinados grupos de personas son especialmente sensibles a las consecuencias del tráfico.

b) Valorar por qué los niños son tan vulnerables a los accidentes.

c) Identificar qué tipo de jóvenes son los que aparecen con mayor frecuencia en las estadísticas de accidentes.

d) Discriminar por qué los peatones son muy vulnerables a los accidentes de tráfico.

e) Distinguir las características que hacen que muchas personas mayores sufran las terribles consecuencias de los accidentes.

f) Apreciar los problemas a los que se enfrentan los ciclistas como usuarios de la vía.

g) Señalar las estrategias y consejos para evitar el accidente con estos grupos de riesgo.

6. La velocidad como factor de riesgo.

a) Apreciar que la velocidad excesiva o inadecuada es uno de los principales factores de riesgo en la conducción.

b) Reconocer que es muy importante controlar la velocidad en función de las características del ambiente, del vehículo y de tu propio estado.

c) Identificar cómo afecta la velocidad a las capacidades del conductor necesarias para una conducción segura.

d) Distinguir el peligro que representa la velocidad excesiva o inadecuada en determinadas maniobras, como el frenado o la toma de curvas.

7. El alcohol como factor de riesgo.

a) Valorar el importante papel que juega el alcohol en los accidentes de tráfico.

b) Identificar los efectos que tiene el alcohol sobre nuestras capacidades para conducir.

c) Discriminar qué influye y qué no influye sobre la tasa de alcoholemia.

d) Tomar conciencia del riesgo que supone conducir bajo los efectos del alcohol.

e) Reconocer la responsabilidad legal que se deriva de una conducción bajo la influencia de las bebidas alcohólicas.

8. Las drogas de abuso como factor de riesgo.

a) Señalar la influencia de las principales drogas de abuso sobre la capacidad de conducción.

b) Valorar los riesgos reales de la conducción bajo la influencia de determinadas drogas. 
c) Distinguir las características de los principales grupos de drogas de abuso.

d) Valorar la relación que hay entre determinadas sustancias legales, como el café, el té o el tabaco, y la conducción de vehículos.

9. Las enfermedades y los fármacos como factores de riesgo.
a) Apreciar cómo muchas enfermedades pueden alterar tu capaci- dad para conducir con seguridad.
b) Identificar, a modo de ejemplo, la influencia de la depresión y de las alergias en el tráfico.
c) Considerar que la conducción cuando se están consumiendo determinados fármacos puede representar un grave riesgo para tu seguridad.
d) Distinguir qué debes hacer ante la enfermedad y los fármacos para garantizar la seguridad en las vías públicas.
e) Tomar conciencia de la necesidad de estar en las mejores con- diciones a la hora de conducir.

10. La somnolencia como factor de riesgo.
a) Apreciar la incidencia que tiene la somnolencia en los acciden- tes de tráfico.
b) Identificar los efectos que produce la somnolencia en el con- ductor.
c) Reconocer las principales causas de somnolencia durante la conducción.
d) Señalar cómo prevenir la aparición de somnolencia al volante.
e) Valorar la relación entre el síndrome de apnea obstructiva del sueño y los accidentes de tráfico.

11. La fatiga como factor de riesgo.
a) Apreciar la incidencia que tiene la fatiga en los accidentes de tráfico.
b) Identificar qué factores pueden potenciar la aparición de la fati- ga.
c) Distinguir qué alteraciones produce la fatiga sobre el conduc- tor.
d) Tomar conciencia del riesgo que supone conducir fatigado.
e) Señalar qué se debe hacer para evitar la fatiga al volante.
f) Valorar la importancia que tiene para la seguridad vial que los conductores profesionales cumplan la reglamentación sobre los tiempos de conducción y descanso.

12. El estrés como factor de riesgo.
a) Apreciar la incidencia que tiene el estrés en los accidentes de tráfico.
b) Identificar qué es el estrés y de qué fases se compone.
c) Discriminar qué tipo de situaciones son estresantes para la mayoría de las personas.


d) Reconocer las consecuencias del estrés sobre la conducción y sobre la salud.

e) Señalar qué se debe hacer para paliar los efectos del estrés al volante.

f) Tomar conciencia del riesgo que conlleva conducir bajo los efectos del estrés.

13. Seguridad activa y pasiva.

a) Identificar los elementos que componen los sistemas de seguridad activa y pasiva de los vehículos automóviles.

b) Apreciar la importancia de una buena utilización de los diferentes elementos de seguridad.

c) Conocer las principales reglas de mantenimiento y cuidado del vehículo y de todos sus sistemas de seguridad.

d) Valorar la importancia del uso de los sistemas de retención infantil.

14. La conducción preventiva.

a) Conocer el concepto y los principios de la conducción preventiva.

b) Valorar la eficacia de la conducción preventiva para reducir los accidentes de tráfico.

c) Identificar las reglas y comportamientos propios de la conducción preventiva.

d) Comprender la importancia de tu propio comportamiento a la hora de evitar los accidentes de tráfico.

e) Conocer los comportamientos adecuados para la conducción en condiciones climatológicas adversas.

f) Promocionar este estilo de conducción más segura entre los conductores.

15. Actuación en caso de accidente de tráfico.

a) Concebir la actuación en caso de accidente como una parte importante dentro de la seguridad vial.

b) Recordar la regla mnemotécnica PAS (Proteger, Alertar, Socorrer), que constituye la pauta básica a seguir en caso de accidente de tráfico.

c) Conocer las actuaciones mínimas para proteger el lugar del accidente, a los implicados en el mismo, a los otros conductores que se aproximen y a las propias personas que prestan la ayuda.

d) Saber qué se debe hacer para alertar con eficacia de lo sucedido a los servicios de urgencia.

e) Conocer las actuaciones mínimas y seguras para socorrer a las víctimas hasta la llegada de los servicios sanitarios de emergencia. 
16. La importancia del cumplimiento de las normas de tráfico.

a) Conocer los principios y valores que deben inspirar en todo momento nuestro comportamiento al circular por las vías públicas.

b) Comprender el importante papel que juega el respeto de las normas de circulación para garantizar la seguridad vial.

c) Saber cuál es la responsabilidad social y legal derivada del incumplimiento de las normas de tráfico.

d) Aprender las principales normas de comportamiento que debemos guardar en la circulación.

El coste de la matriculación a los cursos correrá íntegramente a cargo del interesado. Los conductores que hayan perdido la totalidad de los puntos deben realizar una prueba de control de conocimientos al finalizar los cursos. No se trata de volver a examinarse del examen para obtener el carné, se trata de una prueba específica sobre los contenidos de los cursos.

\subsection{La reforma del Código Penal en materia de tráfico y seguridad vial de 2007}

El consenso en torno a la necesidad de reformar el Código Penal en materia de seguridad vial y sobre la dirección que había de seguir dicha reforma era ya relativamente amplio en 2007. Como se ha visto, la combinación de la vía administrativa con el Código Penal de 2003 se había mostrado claramente insuficiente para lidiar con los problemas a los que debía hacer frente.

Además, la reforma del Código Penal pretendía ser el cierre del sistema. Esto es, primero se habían introducido toda una serie de reformas administrativas con las que regular al conjunto de los conductores, y el Código Penal quedaba ahora como la ultima ratio, el último recurso extraordinario para lidiar con los casos más graves. Sin dicha reforma, las modificaciones en el ámbito administrativo, así como muchas otras innovaciones introducidas, corrían el riesgo de acabar resultando inoperantes o, como mínimo, de no desarrollar todo su potencial ${ }^{36}$. Éste es el caso, por ejemplo, de la conducción sin licencia. Si la única sanción a la que se enfrenta el conductor que conduce sin haber obtenido el permiso o teniéndolo retirado es de tipo administrativo, el carné por puntos pierde todo su poder disuasorio.

${ }^{36}$ Cano (2008), Exposición de Motivos, González (2007), González y Vidales (2008), Ledesma (2008), Mena (2007), Navarro (2008), Perona (2008), Thorson (2008), Villalba (2008). 
Por otra parte, según muchos autores así como la propia Exposición de Motivos de la Ley ${ }^{37}$, la reforma tenía también una voluntad, por así decirlo, pedagógica. Se trataba de aprovechar la "función simbólica" del derecho penal (mucho mayor, según los autores, que la del derecho administrativo) para comunicar a los ciudadanos que las conductas señaladas por la ley resultaban socialmente inaceptables y merecedoras de reproche.

Finalmente la reforma fue aprobada mediante la Ley Orgánica 15/2007, de 30 de noviembre. Cabe destacar que, en el momento de dicha aprobación, el grado de enfrentamiento y crispación entre los dos partidos mayoritarios en el parlamento español era muy importante, y que éste fue uno de los pocos consensos alcanzados entre ambos. Ambos partidos pretendían una reforma en profundidad del Código Penal, pero no lograron alcanzar un acuerdo sobre los contenidos del mismo. Siendo esto así, finalmente alcanzaron un consenso mínimo restringido a lo referente a la seguridad vial. Finalmente el PP se abstuvo en la votación, pero fue suficiente para que la reforma saliese adelante. A favor votaron los grupos del PSOE, CIU, ERC, IU e ICV entre otros. El acuerdo fue posible, en gran parte, por la iniciativa de la Comisión de Seguridad Vial del Congreso y por la presión ejercida por las asociaciones de víctimas que presentaron más de 30.000 firmas en el Congreso pidiendo la reforma (Thorson, 2008).

Como característica general, puede decirse que la reforma continúa la tendencia de los últimos años, compartida por todos los Estados de nuestro entorno, de aumentar la intervención del derecho penal en materia de seguridad vial (Mir, 2008, Vargas, 2007). En total se reforman 7 artículos (ver tabla 1). Las principales modificaciones se dirigen a tratar definir con mayor rigor los delitos contra la seguridad vial y del tráfico a fin de evitar que determinadas conductas queden impunes, señalar de manera clara la alcoholemia y el exceso de velocidad como conductas susceptibles de ser clasificadas como delito (igualando además claramente el tratamiento de la segunda al de la primera) y tipificar como delito la conducción sin carné o con éste retira$\mathrm{do}^{38}$. De manera destacada se produce un salto adelante cualitativo en el tratamiento del alcohol y otras drogas y, por primera vez en la legislación penal, se introducen límites objetivos (Villalba, 2008). De hecho, no parece exagerado decir que la última razón de ser de la reforma es la modificación del tratamiento del alcohol y la velocidad, a saber, de los dos principales factores facilitadores de la accidentalidad y la muerte en la circulación.

Precisamente el cambio en el tratamiento del alcohol y la velocidad ha acarreado una cierta polémica en torno al número de nuevos ilícitos introducidos por la reforma. Algunos autores sostienen que se trata de tres: la con-

${ }^{37}$ Cano (2008), Exposición de Motivos, González (2007), González y Vidales (2008), Perona (2008), Vargas (2007).

${ }^{38}$ Cano (2008), Exposición de Motivos, Jané (2008), Navarro (2008). 
ducción sin carné o con éste retirado, y la conducción a partir de una determinada velocidad o a partir de un determinado nivel de alcohol que pasarán a ser delitos de por sí (Cano, 2007). Otros autores ${ }^{39}$ lo discuten y sostienen que en realidad en lo referente al alcohol no se crea un nuevo ilícito. La cuestión es que no se crea una conducta nueva sino que se mantiene la fórmula "conducir bajo la influencia" y simplemente se añade una tasa a partir de la cual se considera de manera automática que hay influencia.

Por lo que se refiere a la severidad de la reforma, tampoco existe un acuerdo total entre los expertos. Muchos de ellos, así como la propia exposición de motivos de la ley, sostienen que las penas aumentan en severidad ${ }^{40}$. En este sentido, Villalba (2008) argumenta que la reforma continúa en la línea de las sucesivas reformas de los últimos años. En cambio otros autores, algunos de ellos con un papel muy destacado en la reforma como el director de la DGT Pere Navarro (2008), argumentan que el principal objetivo de la reforma era el de lograr mayor concreción, no mayores penas. No obstante, una vez que se aclaran los términos de la cuestión, este parece ser un pseudo-debate. De manera general es cierto que no se crean nuevas penas, ya que la mayoría ya existían. No obstante, es igualmente cierto que apenas se aplicaban y que resultaban inoperantes en la práctica, o sea, que era como si no existiesen. Por tanto, al asegurar su aplicación se incrementa de facto la severidad.

Hasta aquí se han comentado de forma genérica las principales características de la reforma. A continuación, también brevemente, se repasarán los 7 artículos reformados uno por uno.

\subsubsection{ARTí́CULO 47: NUEVO EFECTO DE LA PENA DE PRIVACIÓN DEL DERECHO DE CONDUCIR}

Antes de la reforma, el redactado de este artículo rezaba ${ }^{41}$ :

«La imposición de la pena de privación del derecho a conducir vehículos a motor y ciclomotores inhabilitará al penado para el ejercicio de ambos derechos durante el tiempo fijado en la sentencia.

$(\ldots) »$.

Tras la reforma, el redactado quedó:

«La imposición de la pena de privación del derecho a conducir vehículos a motor y ciclomotores inhabilitará al penado para el

\footnotetext{
${ }^{39}$ González (2007), González y Vidales (2008), Navarro (2008).

${ }^{40}$ Exposición de Motivos, Mena (2007), Mir (2008), Vargas (2007).

${ }^{41}$ Tanto en este como en los siguientes casos se hace referencia sólo a la parte del redactado que tiene que ver con la seguridad vial. Pueden encontrarse los redactados completos en la tabla 1.
} 
ejercicio de ambos derechos durante el tiempo fijado en la sentencia.

(...).

Cuando la pena impuesta lo fuere por un tiempo superior a dos años comportará la pérdida de vigencia del permiso o licencia que habilite para la conducción o la tenencia y porte, respectivamente».

Como puede verse, la modificación consiste en la incorporación de un tercer apartado (destacado en negrita). En dicho apartado se añade un nuevo efecto a la pena de privación del derecho a conducir vehículos a motor y ciclomotores. La pérdida se convierte en definitiva cuando la pena impuesta sea superior a dos años. Dicho cambio se justifica por tres razones distintas. En primer lugar, obviamente, la pena impuesta expresa la gravedad de la infracción cometida. En segundo lugar, el hecho de que el conductor pase más de dos años sin conducir justifica que se tenga que volver a examinar ante la posibilidad de haber perdido pericia. En tercer lugar, el hecho de que se tenga que volver a examinar facilita el control y la reeducación del mismo (González, 2007, González y Vidales, 2008).

\subsubsection{ARTí́CULO 379: EXCESO DE VELOCIDAD Y CONDUCCIÓN BAJO LA INFLUEN- CIA DE BEBIDAS ALCOHÓLICAS Y DROGAS TÓXICAS}

Antes de la reforma este artículo presentaba el siguiente redactado:

«El que condujere un vehículo de motor o ciclomotor bajo la influencia de drogas tóxicas, estupefacientes, sustancias psicotrópicas o de bebidas alcohólicas será castigado con la pena de prisión de tres a seis meses o a la de multa de seis a doce meses y, en su caso, trabajos en beneficio de la comunidad de treinta y uno a noventa días y, en cualquier caso, privación del derecho a conducir vehículos a motor y ciclomotores por tiempo superior a uno y hasta cuatro años».

Tras la reforma, el redactado pasa a ser:

«1. El que condujere un vehículo de motor o un ciclomotor a velocidad superior en sesenta kilómetros por hora en vía urbana o en ochenta kilómetros por hora en vía interurbana a la permitida reglamentariamente, será castigado con la pena de prisión de tres a seis meses o a la de multa de seis a doce meses y trabajos en beneficio de la comunidad de treinta y uno a noventa días, y, en cualquier caso, a la de privación del derecho a conducir vehículos a motor y ciclomotores por tiempo superior a uno y hasta cuatro años. 
2. Con las mismas penas será castigado el que condujere un vehículo de motor o ciclomotor bajo la influencia de drogas tóxicas, estupefacientes, sustancias psicotrópicas o de bebidas alcohólicas. En todo caso será condenado con dichas penas el que condujere con una tasa de alcohol en aire espirado superior a 0,60 miligramos por litro o con una tasa de alcohol en sangre superior a 1,2 gramos por litro».

En este caso las modificaciones son muy sustanciales. Podría decirse que la modificación de este artículo constituye el aspecto fundamental de la reforma.

Se modifica el redactado en lo referente a conducción bajo la influencia del alcohol y las drogas introduciendo, por primera vez en España, unos límites objetivos y claros para la intervención penal y se incluye un nuevo apartado sobre velocidad con límites igualmente objetivos y $\operatorname{claros}^{42}$. La reforma ha buscado también introducir más seguridad jurídica reduciendo la discrecionalidad. Esto permitirá que los operadores jurídicos no tengan duda a la hora de tipificar una determinada conducta de un modo u otro, así como que los ciudadanos sean perfectamente conscientes de cuándo su actuación puede ser constitutiva de delito ${ }^{43}$.

En lo que se refiere al alcohol, el sistema de represión de las conductas en este punto continúa siendo mixto, a saber, se sigue combinando la vía administrativa con la penal (Villalba, 2008), pero ahora se trata de trazar una delimitación objetiva y clara entre lo que constituye un ilícito penal y lo que constituye uno administrativo ${ }^{44} 45$.

Es necesario empero introducir una matización en este punto. A partir de la reforma siempre se clasificará como delito el hecho de conducir con una tasa de alcohol en sangre superior a 1,2 g/l (o 0,6 g/l en aire espirado). Pero esto no significa que no se pueda clasificar como delito la conducción con una tasa de alcohol superior a la legal pero inferior a ese límite. En esos casos el ilícito se clasificará como administrativo, a no ser que se demuestre que el alcohol ha influido sobre las capacidades del conductor en cuyo caso

\footnotetext{
${ }^{42}$ Cano (2008), González (2007), González y Vidales (2008), Jané (2008), Vargas (2007), Villalba (2008).

${ }^{43}$ Cano (2008), González (2007), González y Vidales (2008), Navarro (2008), Villalba (2008).

${ }^{44}$ Cano (2008), González (2007), González y Vidales (2008), Jané (2008), Vargas (2007), Villalba (2008).

${ }^{45}$ No obstante, algunos autores estiman que, si bien los ilícitos penales quedan ahora bien delimitados, los límites fijados (tanto en lo referido a la velocidad como a la alcoholemia) son excesivos y deben ser revisados a la baja acorde con la legislación existente en otros países de nuestro entorno. Véase, por ejemplo, Cano (2008), González (2007) o González y Vidales (2008).
} 
se puede clasificar como delito. A este respecto, por tanto, se mantiene la misma lógica de antes de la reforma. De este modo, la reforma se dirige principalmente a resolver los supuestos más graves. En el resto de casos para clasificar como delito continúa siendo necesario probar que: 1 . se ha consumido alcohol por encima de los límites permitidos, 2. el alcohol afecta a las capacidades y 3 . se ha creado algún riesgo para los bienes jurídicos protegidos. En este sentido, es de esperar que en estos casos sigan existiendo las mismas dificultades que hasta ahora para clasificar como delito. En este sentido, algunos autores apuntan a la necesidad de eliminar también esta ambigüedad reduciendo a la baja la tasa de alcohol del ilícito penal y eliminando el supuesto de conducción «bajo influencia» ${ }^{46}$.

Por lo que se refiere a la velocidad, tal y como se ha argumentado anteriormente, a diferencia del alcohol donde existe un modelo mixto de intervención (administrativo/penal) más o menos consolidado por varias décadas de legislación, la velocidad había tenido en España un tratamiento puramente administrativo hasta fechas muy recientes. Es en la anterior reforma del Código Penal del año 2003 cuando por primera vez se introduce la posibilidad de considerar temeridad manifiesta "un exceso desproporcionado de velocidad respecto de los límites establecidos" (artículo 381). No obstante, como se ha visto, ese supuesto prácticamente nunca se aplicó. Así pues, con la reforma el tratamiento de la velocidad se equipara ya claramente con el del alcohol y tendrá un tratamiento mixto administrativo/penal (Villalba, 2008).

Por otra parte, la reforma se refiere a la velocidad "excesiva" y no a la "inadecuada". Si bien existen razones obvias para que esto sea así ya que la primera es más fácilmente objetivable y detectable a través de medios técnicos, algunos autores critican un cierto abandono del segundo tipo (Villalba, 2008).

En lo referente a los castigos, las penas se mantienen respecto al redactado anterior. Como en otros casos se combinan penas de prisión con penas alternativas a la prisión en forma de multas y trabajos en beneficio de la comunidad. La novedad estriba en que en caso de que se opte por una sanción alternativa a la prisión en forma de multa, los trabajos en beneficio de la comunidad dejan de ser optativos. Como se verá, esto mismo sucede en otros artículos. De este modo, y dado que no es de esperar que los operadores jurídicos opten por no sancionar con penas de prisión en primer término, con la reforma los trabajos en beneficio de la comunidad pasan a tener un rol muy importante en la penalidad. Este hecho habla a favor de la voluntad reeducadora y concienciadora de la reforma, pero a su vez supone un reto importante para el sistema. Resulta fundamental que exista una oferta adecuada y suficiente de trabajos de este tipo (Vargas, 2007).

${ }^{46}$ González (2007), González y Vidales (2008). 


\subsubsection{ARTí́CULO 380: LA CONDUCCIÓN CON TEMERIDAD MANIFIESTA}

El nuevo artículo 380 recoge con modificaciones el antiguo artículo 381. El antiguo 381 rezaba:

«El que condujere un vehículo a motor o un ciclomotor con temeridad manifiesta y pusiere en concreto peligro la vida o la integridad de las personas será castigado con las penas de prisión de seis meses a dos años y privación del derecho a conducir vehículos a motor y ciclomotores por tiempo superior a uno y hasta seis años.

En todo caso, se considerará que existe temeridad manifiesta y concreto peligro para la vida o la integridad de las personas en los casos de conducción bajo los efectos de bebidas alcohólicas con altas tasas de alcohol en sangre y con un exceso desproporcionado de velocidad respecto de los límites establecidos».

El nuevo artículo 380 reza:

«1. El que condujere un vehículo a motor o un ciclomotor con temeridad manifiesta y pusiere en concreto peligro la vida o la integridad de las personas será castigado con las penas de prisión de seis meses a dos años y privación del derecho a conducir vehículos a motor y ciclomotores por tiempo superior a uno y hasta seis años.

2. A los efectos del presente precepto se reputará manifiestamente temeraria la conducción en la que concurrieren las circunstancias previstas en el apartado primero $y$ en el inciso segundo del apartado segundo del artículo anterior».

En este caso nuevamente los cambios en el redactado vuelven a ser sustantivos. Lo primero que se constata es que, al hacer referencia al artículo 379 , el nuevo artículo 380 presenta las mismas mejoras que aquél, a saber, se objetiva cuándo existe conducción temeraria, se reduce la inseguridad jurídica, etc. Del mismo modo, también puede ser sometido a las mismas críticas que aquél. No se volverán a discutir aquí estás cuestiones.

Pero además, se produce una pequeña modificación en el redactado que no debiera pasar desapercibida dado que puede llegar a tener importantes consecuencias. Con el redactado anterior se consideraba que existía temeridad manifiesta siempre que se diese conducción bajo los efectos de bebidas alcohólicas con altas tasas de alcohol en sangre "y" con un exceso desproporcionado de velocidad respecto de los límites establecidos. Esto es, para condenar era necesario que se diesen los tres factores: 1 . altas tasas de alcohol en sangre, 2. que éstas influyesen sobre las capacidades del conductor y 3 . que se condujese a velocidad desproporcionada. En cambio ahora no es necesaria la presencia de todos los factores. Se puede condenar tanto si se produce un exceso de velocidad por encima del límite penal (sin alcohole- 
mia) como si se supera el límite penal de la tasa de alcohol (sin exceso de velocidad) (González, 2007, Hortal, 2008).

Pese a las mejoras, algunos autores critican, no obstante, que se sigan tratando de forma laxa otras formas de temeridad que no tienen que ver con la velocidad ni con el consumo de alcohol o drogas ${ }^{47}$.

Finalmente, en lo referente a la penalidad en este caso se mantiene sin más.

\subsubsection{ARTí́CULO 381: LA CONDUCCIÓN CON MANIFIESTO DESPRECIO POR LA VIDA DE LOS DEMÁS}

El nuevo artículo 381 recoge con modificaciones los antiguos artículos 384 y 385 . El más importante de ambos para lo que aquí nos afecta era el 384. Dicho artículo rezaba:

«Será castigado con las penas de prisión de uno a cuatro años, multa de seis a doce meses y privación del derecho a conducir vehículos a motor y ciclomotores por tiempo superior a seis y hasta diez años el que, con consciente desprecio por la vida de los demás, incurra en la conducta descrita en el artículo 381.

Cuando no se hubiere puesto en concreto peligro la vida o la integridad de las personas, las penas serán de prisión de uno a dos años, manteniéndose el resto de penas».

El nuevo artículo 381 reza:

«1. Será castigado con las penas de prisión de dos a cinco años, multa de doce a veinticuatro meses y privación del derecho a conducir vehículos a motor y ciclomotores durante un período de seis a diez años el que, con manifiesto desprecio por la vida de los demás, realizare la conducta descrita en el artículo anterior.

2. Cuando no se hubiere puesto en concreto peligro la vida o la integridad de las personas, las penas serán de prisión de uno a dos años, multa de seis a doce meses y privación del derecho a conducir vehículos a motor y ciclomotores por el tiempo previsto en el párrafo anterior.

3. El vehículo a motor o ciclomotor utilizado en los hechos previstos en el presente precepto se considerará instrumento del delito a los efectos del artículo 127 de este Código» ${ }^{48}$.

${ }^{47}$ González (2007), González y Vidales (2008), Moreno (2003).

${ }^{48}$ Este tercer párrafo recoge el contenido del antiguo artículo 385. 
En primer lugar, cabe constatar que, como en el caso anterior, en última instancia se hace referencia al redactado del artículo 379 siendo por tanto aplicables los mismos comentarios que se han efectuado entonces.

A nivel más específico, ahora se requiere que el desprecio sea «manifiesto» en lugar de «consciente». La diferencia entre ambos conceptos ya se ha sugerido más arriba. El calificativo «manifiesto» resulta más fácilmente objetivable. Parece más difícil poder dictaminar si alguien era consciente de que estaba conduciendo con desprecio hacia la vida de los demás que si resulta manifiesto (para un observador imparcial) que lo estaba haciendo ${ }^{49}$. De este modo pues, también en este sentido el tipo gana en precisión y operatividad (Mena, 2007).

No obstante, algunos autores (Orts, 2007) sostienen que de manera general, para los casos que no son la conducción sobrepasando una determinada velocidad o tasa de alcohol, el problema sigue siendo el mismo: dictaminar cuándo estamos ante una infracción administrativa, cuándo ante temeridad manifiesta, y cuándo ante manifiesto desprecio. De hecho, Orts califica de irresoluble este problema.

En lo que se refiere a la penalidad, a diferencia de los artículos anteriores, se produce un ligero aumento de la misma.

\subsubsection{ARTí́CULO 382: LAS LESIONES}

El nuevo artículo 382 incorpora el contenido, pero modificado, del antiguo artículo 383. El redactado del antiguo 383 rezaba:

«Cuando con los actos sancionados en los artículos 379, 381 y 382 se ocasionara, además del riesgo prevenido, un resultado lesivo constitutivo de delito, cualquiera que sea su gravedad, los Jueces o Tribunales apreciarán tan sólo la infracción más gravemente penada, condenando, en todo caso, al resarcimiento de la responsabilidad civil que se haya originado.

En la aplicación de las penas establecidas en los citados artículos, procederán los jueces y tribunales según su prudente arbitrio, sin sujetarse a las reglas prescritas en el artículo 66».

El nuevo artículo 382 reza:

«Cuando con los actos sancionados en los artículos 379, 380 y 381 se ocasionare, además del riesgo prevenido, un resultado lesivo constitutivo de delito, cualquiera que sea su gravedad, los Jueces o

\footnotetext{
${ }^{49}$ Por otra parte, con el cambio se homogeniza la terminología ya que el mismo concepto (manifiesto) se utiliza también en el artículo 380 (Mena, 2007).
} 
Tribunales apreciarán tan sólo la infracción más gravemente penada, aplicando la pena en su mitad superior y condenando, en todo caso, al resarcimiento de la responsabilidad civil que se hubiera originado».

En este caso nos encontramos ante modificaciones en el redactado de consecuencias prácticas muy importantes.

En primer lugar, como en los casos anteriores, en última instancia se hace referencia al redactado del artículo 379 siendo por tanto aplicables los mismos comentarios que se han efectuado entonces.

En segundo lugar, se produce un importante aumento de facto de la penalidad dado que ahora sólo puede aplicarse la pena en su mitad superior. Una vez más se reduce el margen de discrecionalidad de jueces y tribunales.

En tercer lugar, la eliminación de la disposición según la cual los jueces no están sujetos a lo previsto por el artículo 66 al tratar este tipo de infracciones supone aun una reducción adicional de la discrecionalidad y una todavía mayor severidad de facto $^{50}$.

\subsubsection{ARTí́culo 383: DESOBEDIENCIA POR NEGATIVA A SOMETERSE A LAS PRUE- BAS DE CONTROL}

El nuevo artículo 383 incorpora el contenido, pero modificado, del antiguo artículo 380. Este artículo se refiere a la negativa a realizar las pruebas de alcoholemia y consumo de drogas. El antiguo artículo 380 rezaba:

«El conductor que, requerido por un agente de la autoridad, se negare a someterse a las pruebas legalmente establecidas para la comprobación de los hechos descritos en el artículo anterior, será castigado como autor de un delito de desobediencia grave, previsto en el artículo 556 de este código».

El nuevo artículo 383 reza:

«El conductor que, requerido por un agente de la autoridad, se negare a someterse a las pruebas legalmente establecidas para la comprobación de las tasas de alcoholemia y la presencia de las drogas tóxicas, estupefacientes y sustancias psicotrópicas a que se refieren los artículos anteriores, será castigado con las penas de prisión de seis meses a un año y privación del derecho a conducir vehículos a motor y ciclomotores por tiempo superior a uno y hasta cuatro años».

${ }^{50}$ Para una discusión de esta cuestión, véase Hortal (2008) y Mena (2007). 
En este caso el único cambio consiste en un endurecimiento de la sanción que, además de la pena de prisión, prevé ahora la retirada del carné de conducir.

Cabe destacar que este artículo resulta fundamental para el conjunto del sistema dado que funciona como un "cierre" del mismo. No tendría ningún sentido sancionar penalmente la conducción habiendo consumido grandes dosis de alcohol si el infractor pudiese negarse a realizar las pruebas necesarias para acreditarlo siendo sancionado sólo administrativamente por ello.

\subsubsection{ARTículo 384: QUEBRANTAMIENTO DE CONDENA O DE RESOLUCióN ADMINISTRATIVA}

El nuevo artículo 384 tipifica un nuevo delito: la conducción habiendo perdido el permiso o sin haberlo obtenido nunca.

«El que condujere un vehículo de motor o ciclomotor en los casos de pérdida de vigencia del permiso o licencia por pérdida total de los puntos asignados legalmente, será castigado con la pena de prisión de tres a seis meses o con la de multa de doce a veinticuatro meses y trabajos en beneficio de la comunidad de treinta y uno a noventa días.

Las mismas penas se impondrán al que realizare la conducción tras haber sido privado cautelar o definitivamente del permiso o licencia por decisión judicial y al que condujere un vehículo de motor o ciclomotor sin haber obtenido nunca permiso o licencia de conducción».

Nuevamente, este artículo vuelve a funcionar como cierre del carné por puntos y, de modo general, de todo el sistema administrativo en lo referente a esta materia ${ }^{51}$. Recuérdese que, como se ha comentado anteriormente, la conducción sin carné y la multireincidencia son dos de los terrenos en los que la vía administrativa se había mostrado más inoperante. Dado que estas cuestiones ya se han discutido más arriba no se volverá aquí sobre las mismas.

En lo referido a la penalidad, obviamente, transformar un ilícito administrativo en uno penal supone un claro agravamiento de la misma.

\subsubsection{ARTículo 385: OTRAS CONDUCTAS DE RIESGO PARA LA SEGURIDAD VIAL}

Finalmente, el nuevo artículo 385 recoge, pero modificado, el antiguo artículo 382. El antiguo artículo 382 rezaba:

${ }^{51}$ González (2007), González y Vidales (2008), Mena (2007), Perona (2008), Villalba (2008). 
«Será castigado con la pena de prisión de seis meses a dos años o a la de multa de doce a veinticuatro meses el que originare un grave riesgo para la circulación de alguna de las siguientes formas:

1. Alterando la seguridad del tráfico mediante la colocación en la vía obstáculos imprevisibles, derramamiento de sustancias deslizantes o inflamables, mutación o daño de la señalización, o por cualquier otro medio.

2. No restableciendo la seguridad de la vía, cuando haya obligación de hacerlo».

El nuevo artículo 385 reza:

«Será castigado con la pena de prisión de seis meses a dos años o a las de multa de doce a veinticuatro meses y trabajos en beneficio de la comunidad de diez a cuarenta días, el que originare un grave riesgo para la circulación de alguna de las siguientes formas:

1. Colocando en la vía obstáculos imprevisibles, derramando sustancias deslizantes o inflamables o mutando, sustrayendo o anulando la señalización o por cualquier otro medio.

2. No restableciendo la seguridad de la vía, cuando haya obligación de hacerlo».

El nuevo artículo 385 mantiene sustancialmente idéntica definición de las conductas que el antiguo 382. El único cambio destacable se refiere a la penalidad. Como en casos anteriores, se incorporan los trabajos en beneficio de la comunidad. Una vez más, se ofrecen dos posibilidades: o pena de prisión o penas alternativas a la prisión. Dichas alternativas consisten en una multa y en la imposición (mandatoria, no optativa) de trabajos en beneficio de la comunidad (González, 2007, González y Vidales, 2008). 
Tabla 1. Comparativa entre la LEY ORGÁNICA 10/1995, de 23 de noviembre, y la LEY ORGÁNICA 15/2007, de 30 de noviembre, del Código Penal en materia de seguridad vial. ${ }^{52}$

Fuente: Elaboración propia a partir de Queralt (2008).

\begin{tabular}{|c|c|}
\hline $\begin{array}{c}\text { Código Penal LEY ORGÁNICA } \\
\text { 10/1995, de } 23 \text { de noviembre, } \\
\text { del Código Penal en materia de } \\
\text { seguridad vial. }\end{array}$ & $\begin{array}{l}\text { LEY ORGÁNICA 15/2007, de } 30 \\
\text { de noviembre, por la que se modifica } \\
\text { la Ley Orgánica 10/1995, de } 23 \text { de } \\
\text { noviembre, del Código Penal en } \\
\text { materia de seguridad vial. }\end{array}$ \\
\hline \multicolumn{2}{|l|}{ Artículo 47} \\
\hline $\begin{array}{l}\text { La imposición de la pena de priva- } \\
\text { ción del derecho a conducir vehículos } \\
\text { a motor y ciclomotores inhabilitará al } \\
\text { penado para el ejercicio de ambos } \\
\text { derechos durante el tiempo fijado en la } \\
\text { sentencia. }\end{array}$ & $\begin{array}{l}\text { La imposición de la pena de priva- } \\
\text { ción del derecho a conducir vehículos } \\
\text { a motor y ciclomotores inhabilitará al } \\
\text { penado para el ejercicio de ambos } \\
\text { derechos durante el tiempo fijado en la } \\
\text { sentencia. }\end{array}$ \\
\hline \multirow[t]{2}{*}{$\begin{array}{l}\text { La imposición de la pena de priva- } \\
\text { ción del derecho a la tenencia y porte } \\
\text { de armas inhabilitará al penado para el } \\
\text { ejercicio de este derecho por el tiempo } \\
\text { fijado en la sentencia }\end{array}$} & $\begin{array}{l}\text { La imposición de la pena de priva- } \\
\text { ción del derecho a la tenencia y porte } \\
\text { de armas inhabilitará al penado para el } \\
\text { ejercicio de este derecho por el tiempo } \\
\text { fijado en la sentencia }\end{array}$ \\
\hline & $\begin{array}{l}\text { Cuando la pena impuesta lo fuere } \\
\text { por un tiempo superior a dos años } \\
\text { comportará la pérdida de vigencia } \\
\text { del permiso o licencia que habilite } \\
\text { para la conducción o la tenencia y } \\
\text { porte, respectivamente. }\end{array}$ \\
\hline \multirow[t]{2}{*}{ Artículo $379^{53}$} & \\
\hline & $\begin{array}{l}\text { 1. El que condujere un vehículo de } \\
\text { motor o un ciclomotor a velocidad } \\
\text { superior en sesenta kilómetros por } \\
\text { hora en vía urbana o en ochenta }\end{array}$ \\
\hline
\end{tabular}

${ }^{52}$ La tabla no incluye las disposiciones transitorias que también se modificaron.

${ }^{53}$ Modificado por la LO 15/2003. Texto anterior: "El que condujere un vehículo a motor o un ciclomotor bajo la influencia de drogas tóxicas, estupefacientes, sustancias psicotrópicas o de bebidas alcohólicas será castigado con la pena de prisión de tres a seis meses o multa de seis a doce meses y, en su caso, trabajos en beneficio de la comunidad de treinta y uno a noventa días y, en cualquier caso, privación del derecho a conducir vehículos a motor y ciclomotores por tiempo superior a uno y hasta cuatro años." 


\begin{tabular}{|c|c|}
\hline $\begin{array}{c}\text { Código Penal LEY ORGÁNICA } \\
\text { 10/1995, de } 23 \text { de noviembre, } \\
\text { del Código Penal en materia de } \\
\text { seguridad vial. }\end{array}$ & $\begin{array}{l}\text { LEY ORGÁNICA 15/2007, de } 30 \\
\text { de noviembre, por la que se modifica } \\
\text { la Ley Orgánica 10/1995, de } 23 \text { de } \\
\text { noviembre, del Código Penal en } \\
\text { materia de seguridad vial. }\end{array}$ \\
\hline & $\begin{array}{l}\text { kilómetros por hora en vía interur- } \\
\text { bana a la permitida reglamentaria- } \\
\text { mente, será castigado con la pena de } \\
\text { prisión de tres a seis meses o a la de } \\
\text { multa de seis a doce meses y trabajos } \\
\text { en beneficio de la comunidad de } \\
\text { treinta y uno a noventa días, y, en } \\
\text { cualquier caso, a la de privación del } \\
\text { derecho a conducir vehículos a } \\
\text { motor y ciclomotores por tiempo } \\
\text { superior a uno y hasta cuatro años. }\end{array}$ \\
\hline $\begin{array}{l}\text { El que condujere un vehículo de } \\
\text { motor o ciclomotor bajo la influencia } \\
\text { de drogas tóxicas, estupefacientes, sus- } \\
\text { tancias psicotrópicas o de bebidas } \\
\text { alcohólicas será castigado con la pena } \\
\text { de prisión de tres a seis meses o a la de } \\
\text { multa de seis a doce meses y, en su } \\
\text { caso, trabajos en beneficio de la comu- } \\
\text { nidad de treinta y uno a noventa días y, } \\
\text { en cualquier caso, privación del dere- } \\
\text { cho a conducir vehículos a motor y } \\
\text { ciclomotores por tiempo superior a } \\
\text { uno y hasta cuatro años. }\end{array}$ & $\begin{array}{l}\text { 2. Con las mismas penas será casti- } \\
\text { gado el que condujere un vehículo de } \\
\text { motor o ciclomotor bajo la influencia } \\
\text { de drogas tóxicas, estupefacientes, sus- } \\
\text { tancias psicotrópicas o de bebidas } \\
\text { alcohólicas. En todo caso será conde- } \\
\text { nado con dichas penas el que condu- } \\
\text { jere con una tasa de alcohol en aire } \\
\text { espirado superior a } 0,60 \text { miligramos } \\
\text { por litro o con una tasa de alcohol en } \\
\text { sangre superior a } \mathbf{1 , 2} \text { gramos por } \\
\text { litro. }\end{array}$ \\
\hline \multicolumn{2}{|l|}{ Artículo 381 Artículo 380} \\
\hline $\begin{array}{l}\text { El que condujere un vehículo a } \\
\text { motor o un ciclomotor con temeridad } \\
\text { manifiesta y pusiere en concreto peli- } \\
\text { gro la vida o la integridad de las perso- } \\
\text { nas será castigado con las penas de pri- } \\
\text { sión de seis meses a dos años y priva- } \\
\text { ción del derecho a conducir vehículos } \\
\text { a motor y ciclomotores por tiempo } \\
\text { superior a uno y hasta seis años. }\end{array}$ & $\begin{array}{l}\text { 1. El que condujere un vehículo a a } \\
\text { motor o un ciclomotor con temeridad } \\
\text { manifiesta y pusiere en concreto peli- } \\
\text { gro la vida o la integridad de las perso- } \\
\text { nas será castigado con las penas de pri- } \\
\text { sión de seis meses a dos años y priva- } \\
\text { ción del derecho a conducir vehículos } \\
\text { a motor y ciclomotores por tiempo } \\
\text { superior a uno y hasta seis años. }\end{array}$ \\
\hline $\begin{array}{l}\text { En todo caso, se considerará que } \\
\text { existe temeridad manifiesta y concreto } \\
\text { peligro para la vida o la integridad de }\end{array}$ & $\begin{array}{l}\text { 2. A los efectos del presente pre- } \\
\text { cepto se reputará manifiestamente } \\
\text { temeraria la conducción en la que }\end{array}$ \\
\hline
\end{tabular}




\begin{tabular}{|c|c|}
\hline $\begin{array}{l}\text { Código Penal LEY ORGÁNICA } \\
\text { 10/1995, de } 23 \text { de noviembre, } \\
\text { del Código Penal en materia de } \\
\text { seguridad vial. }\end{array}$ & $\begin{array}{l}\text { LEY ORGÁNICA } 15 / 2007 \text {, de } 30 \\
\text { de noviembre, por la que se modifica } \\
\text { la Ley Orgánica } 10 / 1995 \text {, de } 23 \text { de } \\
\text { noviembre, del Código Penal en } \\
\text { materia de seguridad vial. }\end{array}$ \\
\hline $\begin{array}{l}\text { las personas en los casos de conduc- } \\
\text { ción bajo los efectos de bebidas alco- } \\
\text { hólicas con altas tasas de alcohol en } \\
\text { sangre y con un exceso despropor- } \\
\text { cionado de velocidad respecto de los } \\
\text { límites establecidos }{ }^{54} \text {. }\end{array}$ & $\begin{array}{l}\text { concurrieren las circunstancias pre- } \\
\text { vistas en el apartado primero y en el } \\
\text { inciso segundo del apartado segundo } \\
\text { del artículo anterior. }\end{array}$ \\
\hline Artículo 384 Artículo 381 & \\
\hline $\begin{array}{l}\text { Será castigado con las penas de pri- } \\
\text { sión de uno a cuatro años, multa de } \\
\text { seis a doce meses y privación del dere- } \\
\text { cho a conducir vehículos a motor y } \\
\text { ciclomotores por tiempo superior a } \\
\text { seis y hasta diez años el que, con cons- } \\
\text { ciente desprecio por la vida de los } \\
\text { demás, incurra en la conducta des- } \\
\text { crita en el artículo } 381 \text {. }\end{array}$ & $\begin{array}{l}\text { 1. Será castigado con las penas de } \\
\text { prisión de dos a cinco años, multa de } \\
\text { doce a veinticuatro meses y privación } \\
\text { del derecho a conducir vehículos a } \\
\text { motor y ciclomotores durante un perí- } \\
\text { odo de seis a diez años el que, con } \\
\text { manifiesto desprecio por la vida de los } \\
\text { demás, realizare la conducta descrita } \\
\text { en el artículo anterior. }\end{array}$ \\
\hline $\begin{array}{l}\text { Cuando no se hubiere puesto en con- } \\
\text { creto peligro la vida o la integridad de } \\
\text { las personas, las penas serán de prisión } \\
\text { de uno a dos años, manteniéndose el } \\
\text { resto de penas. }\end{array}$ & $\begin{array}{l}\text { 2. Cuando no se hubiere puesto en } \\
\text { concreto peligro la vida o la integridad } \\
\text { de las personas, las penas serán de pri- } \\
\text { sión de uno a dos años, multa de seis } \\
\text { a doce meses y privación del derecho } \\
\text { a conducir vehículos a motor y ciclo- } \\
\text { motores por el tiempo previsto en el } \\
\text { párrafo anterior. } \\
\text { 3. El vehículo a motor o ciclomo- } \\
\text { tor utilizado en los hechos previstos } \\
\text { en el presente precepto se considera- } \\
\text { rá instrumento del delito a los efec- } \\
\text { tos del artículo } 127 \text { de este Código. }\end{array}$ \\
\hline
\end{tabular}

${ }^{54}$ Párrafo añadido por la LO 15/2003. 


\begin{tabular}{|c|c|}
\hline $\begin{array}{c}\text { Código Penal LEY ORGÁNICA } \\
\text { 10/1995, de } 23 \text { de noviembre, } \\
\text { del Código Penal en materia de } \\
\text { seguridad vial. }\end{array}$ & $\begin{array}{l}\text { LEY ORGÁNICA 15/2007, de } 30 \\
\text { de noviembre, por la que se modifica } \\
\text { la Ley Orgánica 10/1995, de } 23 \text { de } \\
\text { noviembre, del Código Penal en } \\
\text { materia de seguridad vial. }\end{array}$ \\
\hline $\begin{array}{l}\text { Artículo } 383 \text { Artículo } 382 \\
\text { Cuando con los actos sancionados } \\
\text { en los artículos } 379,381 \text { y } 382 \text { se oca- } \\
\text { sionara, además del riesgo prevenido, } \\
\text { un resultado lesivo constitutivo de } \\
\text { delito, cualquiera que sea su gravedad, } \\
\text { los Jueces o Tribunales apreciarán tan } \\
\text { sólo la infracción más gravemente } \\
\text { penada, condenando, en todo caso, al } \\
\text { resarcimiento de la responsabilidad } \\
\text { civil que se haya originado. } \\
\text { En la aplicación de las penas esta- } \\
\text { blecidas en los citados artículos, pro- } \\
\text { cederán los jueces y tribunales según } \\
\text { su prudente arbitrio, sin sujetarse a } \\
\text { las reglas prescritas en el artículo 66. }\end{array}$ & $\begin{array}{l}\text { Cuando con los actos sancionados } \\
\text { en los artículos } 379,380 \text { y } 381 \text { se oca- } \\
\text { sionare, además del riesgo prevenido, } \\
\text { un resultado lesivo constitutivo de } \\
\text { delito, cualquiera que sea su gravedad, } \\
\text { los Jueces o Tribunales apreciarán tan } \\
\text { sólo la infracción más gravemente } \\
\text { penada, aplicando la pena en su } \\
\text { mitad superior y condenando, en todo } \\
\text { caso, al resarcimiento de la responsa- } \\
\text { bilidad civil que se hubiera originado. }\end{array}$ \\
\hline $\begin{array}{l}\text { Artículo } 380 \text { Artículo } 383 \\
\text { El conductor que, requerido por un } \\
\text { agente de la autoridad, se negare a } \\
\text { someterse a las pruebas legalmente } \\
\text { establecidas para la comprobación de } \\
\text { los hechos descritos en el artículo } \\
\text { anterior, será castigado como autor } \\
\text { de un delito de desobediencia grave, } \\
\text { previsto en el artículo } 556 \text { de este } \\
\text { código. }\end{array}$ & $\begin{array}{l}\text { El conductor que, requerido por un } \\
\text { agente de la autoridad, se negare a } \\
\text { someterse a las pruebas legalmente } \\
\text { establecidas para la comprobación de } \\
\text { las tasas de alcoholemia y la presen- } \\
\text { cia de las drogas tóxicas, estupefa- } \\
\text { cientes y sustancias psicotrópicas a } \\
\text { que se refieren los artículos anterio-- } \\
\text { res, será castigado con las penas de } \\
\text { prisión de seis meses a un año y pri- } \\
\text { vación del derecho a conducir vehí- } \\
\text { culos a motor y ciclomotores por } \\
\text { tiempo superior a uno y hasta cuatro } \\
\text { años. } \\
\text { Artículo } 384 \\
\text { El que condujere un vehículo de } \\
\text { motor o ciclomotor en los casos de }\end{array}$ \\
\hline
\end{tabular}




\begin{tabular}{|c|c|}
\hline $\begin{array}{c}\text { Código Penal LEY ORGÁNICA } \\
\text { 10/1995, de } 23 \text { de noviembre, } \\
\text { del Código Penal en materia de } \\
\text { seguridad vial. }\end{array}$ & $\begin{array}{l}\text { LEY ORGÁNICA } 15 / 2007 \text {, de } 30 \\
\text { de noviembre, por la que se modifica } \\
\text { la Ley Orgánica 10/1995, de } 23 \text { de } \\
\text { noviembre, del Código Penal en } \\
\text { materia de seguridad vial. }\end{array}$ \\
\hline & $\begin{array}{l}\text { pérdida de vigencia del permiso o } \\
\text { licencia por pérdida total de los pun- } \\
\text { tos asignados legalmente, será casti- } \\
\text { gado con la pena de prisión de tres a } \\
\text { seis meses o con la de multa de doce a } \\
\text { veinticuatro meses y trabajos en bene- } \\
\text { ficio de la comunidad de treinta y uno } \\
\text { a noventa días. } \\
\text { Las mismas penas se impondrán al } \\
\text { que realizare la conducción tras haber } \\
\text { sido privado cautelar o definitivamente } \\
\text { del permiso o licencia por decisión } \\
\text { judicial y al que condujere un vehí- } \\
\text { culo de motor o ciclomotor sin haber } \\
\text { obtenido nunca permiso o licencia } \\
\text { de conducción. }\end{array}$ \\
\hline Artículo 382 Artículo 385 & \\
\hline $\begin{array}{l}\text { Será castigado con la pena de prisión } \\
\text { de seis meses a dos años o a la de mul- } \\
\text { ta de doce a veinticuatro meses el que } \\
\text { originare un grave riesgo para la circu- } \\
\text { lación de alguna de las siguientes for- } \\
\text { mas: }\end{array}$ & $\begin{array}{l}\text { Será castigado con la pena de prisión } \\
\text { de seis meses a dos años o a las de } \\
\text { multa de doce a veinticuatro meses y } \\
\text { trabajos en beneficio de la comuni- } \\
\text { dad de diez a cuarenta días, el que } \\
\text { originare un grave riesgo para la circu- } \\
\text { lación de alguna de las siguientes for- } \\
\text { mas: }\end{array}$ \\
\hline $\begin{array}{l}\text { 1. Alterando la seguridad del tráfico } \\
\text { mediante la colocación en la vía obstá- } \\
\text { culos imprevisibles, derramamiento de } \\
\text { sustancias deslizantes o inflamables, } \\
\text { mutación o daño de la señalización, o } \\
\text { por cualquier otro medio. }\end{array}$ & $\begin{array}{l}\text { 1. Colocando en la vía obstáculos } \\
\text { imprevisibles, derramando sustancias } \\
\text { deslizantes o inflamables o mutando, } \\
\text { sustrayendo o anulando la señaliza- } \\
\text { ción o por cualquier otro medio. }\end{array}$ \\
\hline $\begin{array}{l}\text { 2. No restableciendo la seguridad de } \\
\text { la vía, cuando haya obligación de } \\
\text { hacerlo. }\end{array}$ & $\begin{array}{l}\text { 2. No restableciendo la seguridad de } \\
\text { la vía, cuando haya obligación de } \\
\text { hacerlo. }\end{array}$ \\
\hline
\end{tabular}




\subsection{Otros cambios relevantes}

Pese a que la reforma de la Ley de Tráfico y Seguridad Vial, merced a la cuál se creó el carné por puntos, y la posterior reforma del Código Penal han sido las dos transformaciones más importantes llevadas a cabo en España en los últimos años en materia de seguridad vial, no han sido las únicas. A lo largo de este tiempo se han producido otros muchos cambios sin los cuales las citadas reformas no habrían sido posibles o habrían perdido gran parte de su sentido. En esta sección se enumeran brevemente algunos de esos otros cambios.

En 2004 la subcomisión parlamentaria de Seguridad Vial y Prevención de los Accidentes de Tráfico se transformó en comisión y pasó a ser presidida por el convergente Jordi Jané. Cabe destacar que esa elección no fue casual, sino que respondía al hecho de que Catalunya llevaba ya algunos años aplicando una política de seguridad vial coherente y decidida que por aquel entonces estaba ya dando frutos. De dicha comisión partieron la mayoría de iniciativas llevadas a cabo durante los años posteriores.

Paralelamente, el año 2006 la Fiscalía General del Estado creó oficialmente una fiscalía especializada en temas de seguridad vial al frente de la cual se situó al magistrado Bartolomé Vargas ${ }^{55}$. En los últimos años se ha producido un importante impulso en la forma en que el Ministerio Fiscal ha venido abordando los asuntos relacionados con el tráfico y la seguridad vial. Se han venido nombrando fiscales especializados en cada provincia, se han incrementado las actuaciones y la propia Memoria Anual del Ministerio Fiscal dedica un apartado específico a la seguridad vial (Jané, 2008). Además, el Fiscal General del Estado ha comparecido en diversas ocasiones en el Congreso para dar cuenta de las actuaciones en esta materia (Pumpido, 2007, Vargas, 2007).

También en el terreno judicial es necesario destacar la relevancia de la aplicación de los denominados «juicios rápidos» en esta materia (Villalba, 2008). La aplicación de este tipo de procedimientos a los delitos relacionados con el tráfico y la seguridad vial, que por el momento está funcionando adecuadamente (Ulla, 2008), tienen algunas virtudes que merece la pena destacar. El ciudadano recibe personal y rápidamente la sanción con lo que aumenta el efecto pedagógico de ésta no sólo respecto al procedimiento administrativo sino también al penal convencional.

No obstante, pese a estas mejoras, otros autores (Salom, 2008) siguen denunciando la crónica falta de medios de la Fiscalía y de los operadores jurídicos en general que conduce a que muchos de los problemas identificados más arriba no se hayan solucionado.

${ }^{55}$ Una vez más, cabe destacar que la iniciativa en este sentido proviene también desde Catalunya. En el año 2000 el Fiscal Jefe del Tribunal Superior de Catalunya, José María Mena, ya había nombrado un Fiscal Especial para Asuntos de Tráfico. El cargo, el primero de estas características en el Estado, recayó en el magistrado Antoni Vicens. 
En otro orden de cosas, además de la introducción del carné por puntos y de los cursos de sensibilización, a lo largo de estos años la vía administrativa también se ha tratado de mejorar estableciendo limitaciones más severas en lo referido al alcohol, así como pasando de leves a graves numerosas infracciones aumentando de ese modo la severidad en la sanción de las mismas (Navarro, 2008).

Un hito muy destacado en la planificación de la política de seguridad vial lo constituye la elaboración del Plan Estratégico de Seguridad Vial 2005-2008 por parte de la DGT. De dicho plan han surgido medidas como el carné por puntos, la extensión de los dispositivos técnicos de vigilancia, la creación del Observatorio Nacional de la Seguridad Vial, la potenciación del Consejo Superior de Seguridad Vial o las sugerencias de modificaciones legislativas llevadas a cabo en los últimos tiempos (Pumpido, 2007).

En lo referido a la extensión de las nuevas tecnologías (más allá de los radares y los alcoholímetros a los que se hará referencia específica más adelante), si bien se han impulsado algunas pruebas piloto, hay que decir que las iniciativas han sido muy tímidas siendo este probablemente uno de los terrenos en los que se da más espacio para la mejora de cara a los próximos años. Hoy en día existen ya mecanismos como el ESP (sistema de control electrónico de la estabilidad) que ayuda a evitar distracciones y que no se instalan de manera general en los vehículos. Otro dispositivo novedoso es el Alcolock. Este dispositivo consiste en un alcoholímetro incorporado al vehículo. El conductor tiene que someterse a una prueba antes de arrancar el vehículo y si la cantidad de alcohol en aire detectada es excesiva el vehículo no arranca. En países como EEUU, Canadá o Australia este dispositivo se utiliza con éxito con conductores reincidentes en delitos de conducción ebria. Suecia se ha fijado el objetivo de instalarlo en todos los vehículos nuevos de uso profesional para 2010 y en todos los vehículos nuevos sin excepción para 2012. La Comisión Europea está llevando a cabo una prueba piloto y actualmente está siendo probado en España (autobuses de Valladolid) y Noruega en vehículos de transporte público, y en Alemania en el transporte de mercancías peligrosas. Finalmente, una asignatura pendiente en este terreno continúa siendo la instalación de limitadores de velocidad en los vehículos (Vicente, 2007).

Siendo lo anterior sin duda importante, una vez más, aun a riesgo de resultar reiterativo, es necesario poner el acento en el rol absolutamente fundamental de los instrumentos de control del alcohol y la velocidad. Como se ha explicitado a lo largo de estas páginas, el alcohol y la velocidad son los dos factores desencadenantes de accidentes de tráfico cuantitativamente más importantes. En este sentido, gran parte de las reformas legales, en especial en lo referido a la reforma del Código Penal, han ido dirigidas a tratar de mejorar la conducta de los conductores en estas dos áreas. Pero, una vez más, de nada sirven las reformas legales si no se ponen sobre la mesa los medios necesarios para detectar los incumplimientos. 
En lo que se refiere a los controles de alcoholemia cabe destacar que se ha producido un importante aumento tanto en la cantidad como en la sistematicidad de los mismos. La tabla 2 resume el número de controles efectuados en España anualmente por la DGT entre 2003 y 2008.

\section{Tabla 2. Número de controles de alcoholemia llevados a cabo por la DGT.}

Fuente: Elaboración propia a partir de los datos de la DGT.

\begin{tabular}{|c|c|}
\hline Año & Número de controles \\
\hline 2003 & 2.063 .638 \\
2004 & 2.718 .666 \\
2005 & 3.302 .806 \\
2006 & 3.835 .437 \\
2007 & 4.273 .488 \\
2008 & 5.087 .873 \\
\hline
\end{tabular}

Como puede observarse, el número de controles se ha más que doblado en 5 años. Pero además, a esos controles habría que sumar los llevados a cabo en Catalunya por el SCT así como los efectuados por el organismo competente en Euskadi, y los efectuados por las policías locales en los municipios.

Pero el aumento no ha sido sólo cuantitativo, otro cambio de carácter más cualitativo consiste en la mayor sistematicidad de los mismos. Hoy en día los diferentes organismos responsables de la seguridad vial trabajan de manera más coordinada y llevan acabo controles más sistemáticos en determinados momentos como puedan ser las noches de los fines de semanas o las fiestas navideñas.

En lo que se refiere a la velocidad, actualmente en las carreteras españolas la DGT tiene desplegados más de 500 radares fijos y más de 250 móviles, y el objetivo es alcanzar los 2000 radares fijos en 2011. A esos habría que sumar los más de 150 que tiene cedidos a las policías locales, así los que tiene desplegados en Catalunya el SCT y el organismo competente en el Euskadi. En Catalunya, que fue también pionera en este terreno, el SCT tiene ya desplegados más de 115 radares fijos y el número aumenta en unos 30 o 40 anuales (Thorson, 2008).

En definitiva, una de las características más importantes de la nueva política de seguridad vial consiste en la decidida extensión de los controles del alcohol y la velocidad (Navarro, 2008, Thorson, 2008). No obstante, estos son todavía insuficientes y España continúa aún estando a la cola de la UE en este terreno (González y Vidales, 2008, Perona, 2008). 


\section{Conclusiones}

A lo largo del presente trabajo se ha sostenido que la conducta de los conductores (el denominado "factor humano") se encuentra detrás de la gran mayoría de los accidentes de tráfico tanto en España como en el conjunto de los países occidentales. De entre todos los factores que conforman ese factor humano, los dos más importantes en términos cuantitativos son el alcohol y la velocidad. Esas dos son, por tanto, las principales dimensiones sobre las que debe tratar de incidir la política de seguridad vial (aunque obviamente sin por ello desatender las demás).

En lo referente a la modificación de la conducta de los conductores, la política de seguridad vial actúa a través de tres ejes básicos no siempre fácilmente diferenciables entre sí: la educación vial, la propaganda y lo estrictamente referido al diseño institucional (las leyes y sus instrumentos de aplicación). El presente trabajo ha puesto el acento en este último eje, el cual ha sufrido transformaciones muy importantes en los últimos años.

Se ha sostenido que la política de seguridad vial había sido tradicionalmente errática en España. El problema no era percibido como tal por el conjunto de la población, y tanto las leyes como sus instrumentos de aplicación eran insuficientes y estaban mal diseñados.

Pese a que éste es, lógicamente, un proceso de largo alcance, a partir de 2004 se produce un salto adelante cualitativo en este terreno. Entre otros muchos cambios, se modifica la Ley de Tráfico y Seguridad Vial para introducir el denominado carné por puntos, se reforma el Código Penal con el objetivo básico de definir mejor los delitos relacionados con la seguridad vial, y se aumentan de manera considerable los mecanismos de control del alcohol y la velocidad en las carreteras.

\section{Bibliografía}

BLASCO, J.L., «Prueba, presunción de inocencia y proporcionalidad en el procedimiento sancionador en materia de tráfico», en VIDALES, C. y MERA, A. (coords.): Seguridad Vial: (Especial referencia a la reforma operada en el Código Penal mediante la Ley Orgánica 15/2007, de 30 de noviembre), Tirant lo Blanch, València, 2008.

BoIX, J., ORTS, E. y VIVES, T. S., La reforma penal de 1989, Tirant lo Blanch, València, 1989.

CAMPO, A. M., «Reflexiones sobre la delincuencia vial», MiR, S., CORCOY M. y Cardenal, S. (eds.): Seguridad Vial y Derecho Penal. Análisis de la LO 15/2007 que modifica el Código Penal en materia de seguridad vial, Tirant lo Blanch, València, 2008.

CAno, T., «Derecho Penal y Seguridad Vial», en Cano, T. et al. (eds.): Derecho Penal y Seguridad Vial, Ministerio de Justicia: Centro de Estudios Jurídicos: Thomson Aranzadi, Cizur Menor, 2008. 
CARDEnAl, S., «La protección penal de la seguridad vial en el derecho comparado», en Mir, S., Corcoy, M. y CARdenal, S. (eds.): Seguridad Vial y Derecho Penal. Análisis de la LO 15/2007 que modifica el Código Penal en materia de seguridad vial, Tirant lo Blanch, València, 2008.

CorCOY, M., «Homicidio y lesiones imprudentes cometidos con vehículos a motor o ciclomotor», en DE VICENTE, R. (dir.): Derecho Penal y Seguridad Vial, Consejo General del Poder Judicial. Centro de Documentación Judicial, Madrid, 2007.

Corcoy, M., «Homicidio y lesiones en el ámbito del tráfico viario», en MiR, S., Corcoy, M. y Cardenal, S. (eds.): Seguridad Vial y Derecho Penal. Análisis de la LO 15/2007 que modifica el Código Penal en materia de seguridad vial, Tirant lo Blanch, València, 2008.

Cremades \& Calvo-Sotelo Abogados, El carné por puntos. Editorial Arguval, Madrid, 2006.

Domènech, E., Comunicación personal, 2008.

Gómez, P., El Delito De Conducción Bajo La Influencia De Bebidas Alcohólicas, Drogas Tóxicas y Estupefacientes, Bosch, Barcelona, 1998.

GoNZÁLEZ, J. L., «La reforma penal de los delitos contra la seguridad vial (Proyecto CP 2006)», en DE VICENTE, R. (dir.): Derecho Penal y Seguridad Vial, Consejo General del Poder Judicial. Centro de Documentación Judicial, Madrid, 2007.

González, J. L. y Vidales, C., «Los nuevos delitos contra la Seguridad Vial», en Vidales, C. y Mera, A. (coords.): Seguridad Vial: (Especial referencia a la reforma operada en el Código Penal mediante la Ley Orgánica 15/2007, de 30 de noviembre), Tirant lo Blanch, València, 2008.

HorTAL, J. C., «El delito de conducción temeraria (Arts. 379.1 y 2 in fine y 380): Algunas reflexiones al hilo de las últimas reformas», en MIR, S., Corcoy, M. y CARdenal, S. (coords.): Seguridad Vial y Derecho Penal. Análisis de la LO 15/2007 que modifica el Código Penal en materia de seguridad vial, Tirant lo Blanch, València, 2008.

JanÉ, J., «Prólogo», en Cano, T. et al. (eds.): Derecho Penal y Seguridad Vial., Ministerio de Justicia: Centro de Estudios Jurídicos, Thomson Aranzadi, Cizur Menor, 2008.

Ledesma, R., «Debate», en CAno, T. et al. (eds.): Derecho Penal y Seguridad Vial., Ministerio de Justicia: Centro de Estudios Jurídicos, Thomson Aranzadi, Cizur Menor, 2008.

MartíneZ, A., «Derecho Penal y Seguridad Vial», en CANo, T. et al. (eds.): Derecho Penal y Seguridad Vial., Ministerio de Justicia: Centro de Estudios Jurídicos, Thomson Aranzadi, Cizur Menor, 2008.

MenA, J.M., «El delito de conducción temeraria», en DE VICENTE, R. (dir.): Derecho Penal y Seguridad Vial, Consejo General del Poder Judicial. Centro de Documentación Judicial, Madrid, 2007. 
Mir, S., «Presentación», en Mir, S., Corcoy, M. y Cardenal, S. (eds.): Seguridad Vial y Derecho Penal. Análisis de la LO 15/2007 que modifica el Código Penal en materia de seguridad vial, Tirant lo Blanch, València, 2008.

MonTORO, L., «Tráfico y seguridad vial: 6.000 años de historia», en Olives, J. (coord.): Antropologia viària: un enfocament humanístic, Fundació Castellet del Foix - Departament d'Humanitats de la Universitat Internacional de Catalunya, Barcelona, 2003.

MonTORO, L., «Estrategias para la prevención de los accidentes de tráfico», VIDALES, C. y Mera, A. (coords.): Seguridad Vial: (Especial referencia a la reforma operada en el Código Penal mediante la Ley Orgánica 15/2007, de 30 de noviembre), Tirant lo Blanch, València, 2008.

Montoro, L. y RoCA, J., El permiso por puntos: percepción de los conductores. Una investigación sociológica para evaluar el impacto inicial del permiso por puntos en la población española. Informe de investigación, Arag, Barcelona, 2007.

Montoro, L., RocA, J. y Tortosa, F., «Influence of the penalty point system on driving behaviour: drivers' point of view», Psicothema, Vol. 20/4, 2008, pp. 652-658.

Moreno, M. A., Los delitos de conducción temeraria, Tirant lo Blanch, València, 2003.

Moreno, M. A., «La criminalización de las conductas temerarias en el marco de la nueva reforma en materia de seguridad vial», en VIDALES, C. y MERA, A. (coords.): Seguridad Vial: (Especial referencia a la reforma operada en el Código Penal mediante la Ley Orgánica 15/2007, de 30 de noviembre), Tirant lo Blanch, València, 2008.

Navarro, P., «Debate», en CANo, T. et al. (eds.): Derecho Penal y Seguridad Vial., Ministerio de Justicia: Centro de Estudios Jurídicos, Thomson Aranzadi, Cizur Menor, 2008.

ORTS, E., «Conducción con consciente desprecio por la vida de los demás», en DE Vicente, R. (dir.): Derecho Penal y Seguridad Vial, Consejo General del Poder Judicial. Centro de Documentación Judicial, Madrid, 2007.

Pérez, M. A., Diseño de una carretera versus el comportamiento de los conductores. Projecte de Tesina d'Especialitat. Director: Ole Thorson. Universitat Politècnica de Catalunya, 2003.

Perona, A., «Delitos contra la seguridad en el tráfico», en Mir, S., Corcoy, M. y Cardenal, S. (eds.): Seguridad Vial y Derecho Penal. Análisis de la LO 15/2007 que modifica el Código Penal en materia de seguridad vial, Tirant lo Blanch, València, 2008.

PumPIDO, C., «La posición del MF sobre la seguridad vial y prevención de accidentes de tráfico», Ponencia presentada en las Jornadas de Siniestralidad Vial de Albarracín, 2007.

QueRALT, J. J., «Tabla comparativa entre el CP y la Proposición de Ley Orgánica por la que se modifica el CP en materia de seguridad vial», en MIR, 
S., Corcoy, M. y Cardenal, S. (eds.): Seguridad Vial y Derecho Penal. Análisis de la LO 15/2007 que modifica el Código Penal en materia de seguridad vial, Tirant lo Blanch, València, 2008.

SALOM, J. S., «Los delitos contra la seguridad vial en la práctica forense», en VIDALES, C. y Mera, A. (coords.): Seguridad Vial: (Especial referencia a la reforma operada en el Código Penal mediante la Ley Orgánica 15/2007, de 30 de noviembre), Tirant lo Blanch, València, 2008.

Thorson, O., Comunicación personal (entrevista personal e intercambio de correos), 2008.

TORTOSA, F., «El factor humano en los accidentes de tráfico», en VIDALES, C. y Mera, A. (coords.): Seguridad Vial: (Especial referencia a la reforma operada en el Código Penal mediante la Ley Orgánica 15/2007, de 30 de noviembre), Tirant lo Blanch, València, 2008.

Tortosa, F., Montoro, L., Roca, J. y Civera, C., «Los Centros de reconocimiento de conductores veinte años después», Intervención Psicosocial, Vol. 17, núm. 1, 2008, pp. 7-22.

Ulla, J. L., «Debate», en CANo, T. et al. (eds.): Derecho Penal y Seguridad Vial., Ministerio de Justicia: Centro de Estudios Jurídicos, Thomson Aranzadi, Cizur Menor, 2008.

VALDÉs, A., Ingeniería de tráfico, Editorial Dossat, Barcelona, 1978.

VARGAS, B., «El delito de conducción bajo la influencia de bebidas alcohólicas y drogas tóxicas del art. $379 \mathrm{CP} »$, en DE VICENTE, R. (dir.): Derecho Penal y Seguridad Vial, Consejo General del Poder Judicial, Centro de Documentación Judicial, Madrid, 2007.

VICENTE, R. DE, «La reforma penal en curso en materia de seguridad vial», en DE Vicente, R. (dir.): Derecho Penal y Seguridad Vial, Consejo General del Poder Judicial. Centro de Documentación Judicial, Madrid, 2007.

Villalba, F. J., «El endurecimiento de las penas de los delitos de tráfico como medida de mejora de la siniestralidad», en MIR, S., CORCOY, M. y Cardenal, S. (eds.): Seguridad Vial y Derecho Penal. Análisis de la LO 15/2007 que modifica el Código Penal en materia de seguridad vial, Tirant lo Blanch, València, 2008. 